Portland State University

PDXScholar

$1-1-2010$

\title{
Current Assessment and Treatment Practices for Children with Autism and Suspected Childhood Apraxia of Speech: A Survey of Speech-Language Pathologists
}

Elsa Jayne Dawson

Portland State University

Follow this and additional works at: https://pdxscholar.library.pdx.edu/open_access_etds Let us know how access to this document benefits you.

\section{Recommended Citation}

Dawson, Elsa Jayne, "Current Assessment and Treatment Practices for Children with Autism and Suspected Childhood Apraxia of Speech: A Survey of Speech-Language Pathologists" (2010). Dissertations and Theses. Paper 29.

https://doi.org/10.15760/etd.29

This Thesis is brought to you for free and open access. It has been accepted for inclusion in Dissertations and Theses by an authorized administrator of PDXScholar. Please contact us if we can make this document more accessible: pdxscholar@pdx.edu. 
Current Assessment and Treatment Practices for Children with Autism and Suspected Childhood Apraxia of Speech: A Survey of Speech-Language Pathologists

\section{by}

Elsa Jayne Dawson

A thesis submitted in partial fulfillment of the requirements for the degree of

Master of Science

in

Speech and Hearing Sciences

Thesis Committee:

Christina Gildersleeve-Neumann, Chair

Amy Donaldson

Rik Lemoncello

Portland State University

(C)2010 


\begin{abstract}
Purpose: The occurrence of similar speech and non-speech behaviors in some children with autism and Childhood Apraxia of Speech (CAS) calls for the consideration of CAS in some children with autism. The majority of research on CAS has been conducted with children who are otherwise typically developing. The purpose of this study was to determine whether and to what extent children with autism are being diagnosed with or suspected to have CAS as well as what assessment and treatment methods are currently being used with these children.
\end{abstract}

Method: A nationwide survey of speech-language pathologists (SLPs) working with children ages 0-6 years was distributed through snowball sampling, e-mail distribution lists and Facebook discussion pages. The survey requested information on numbers of children served with autism and suspected CAS as well as the criteria used to identify CAS in children with autism and the treatment methods being used in intervention.

Results: 132 surveys were received and analyzed. SLPs from across the United States participated in the study. The mean number of children with autism currently served per participant was 6 children and the mean number of children with autism and suspected CAS per participant was 1. Participants reported suspected CAS in $16 \%$ of children with autism. SLPs working in the field the longest and those serving more total children with autism were suspecting CAS in children with autism more often than other participants. 
Of the total participants, $80 \%$ indicated that they would begin assessment for CAS in a child with autism as soon as they notice specific signs of CAS. The most common markers used were difficulty combining and sequencing phonemes and inconsistent production of speech sounds. Participants reported using a wide range of assessment tools to assess for CAS in a child with autism. Participants tended to rely upon informal assessment measures for this population; the most common assessment tool was a connected speech sample. The most commonly used intervention technique with this population was AAC; participants also reported high familiarity with PROMPT as a treatment for CAS. The least commonly used intervention technique was integral stimulation; $62 \%$ of the participants indicated that they have no knowledge of the technique.

Conclusion: Results revealed that on average, SLPs are suspecting CAS in approximately 1 in 5 children with autism but much fewer children with autism have a second diagnosis of CAS. The decision of when to assess a child with autism for CAS as well as the assessment tools used varied greatly across participants. Participants reported using up to 22 different diagnostic markers to identify CAS in a child with autism. It was also discovered that not all of the traditional diagnostic markers for CAS should necessarily be considered diagnostic markers of CAS in a child with autism (e.g. suprasegmental abnormalities). With no scientific research to date regarding treatment efficacy for the treatment of CAS in children with autism, SLPs are forced to rely on anecdotal data when selecting a treatment to target CAS in a child with autism; SLPs may 
not be using the most effective treatment methods for this population. Results of the study support continued investigation of CAS in children with autism. There is a strong need for the development of clear diagnostic guidelines for CAS in a child with autism as well as reliable assessment tools that should be used. Further studies are needed to identify the most effective treatment approach for children with CAS and autism and how an SLP should incorporate that treatment into an overall comprehensive treatment approach for autism. 
Table of Contents

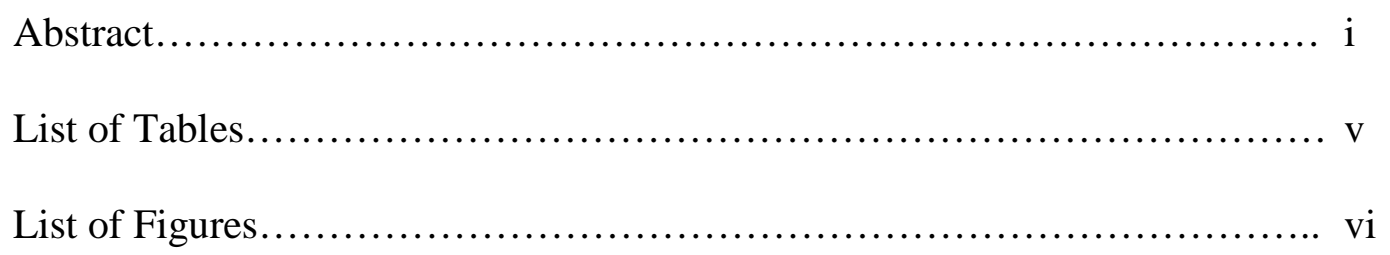

Literature Review................................................ 1

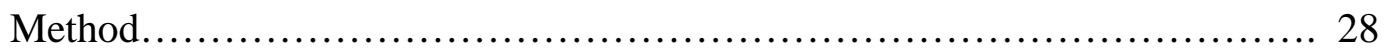

Results......................................................... 34

Discussion....................................................... 57

Conclusion......................................................... 82

References.................................................... 88

Appendices
A. Consent Letter for E-mail Distribution Lists
B. Consent Letter for Facebook Discussion Pages.................... 104
C. Consent Letter for Snowball Sampling.......................... 105
D. Autism and Childhood Apraxia of Speech Survey................ 106 


\section{List of Tables}

Table 1

Distribution of Participants by Region and State.

Table 2

Other Professionals who Participants Report Collaborating With...................

Table 3

Total Number of Children from All Responses for Each Population of Interest and Mean Number of Children Served per Participant.......................

Table 4

Mean Percentage of Children with Autism Who Meet

Characteristics of the Populations of Interest.

Table 5

Percentage of Participants in Each Work Setting Who

Report Suspecting CAS in At Least One Child with Autism 


\section{List of Figures}

Figure 1

Distribution of Participants by Region

Figure 2

Distribution of Participants across Work Settings.

Figure 3

Participants' Opinions on the Assumption that a Core Deficit

in Pragmatics is Sufficient for a Diagnosis of Autism.

Figure 4

Participants' Opinions on the Assumption that Children with

Autism who are Nonverbal Frequently have CAS.

Figure 5

Participants' Opinions on the Assumption that Effective

Treatment for CAS Should Show Immediate Improvement.

Figure 6

Participants' Opinions on the Assumption that All Three Areas of

Deficit Highlighted in ASHA's 2007 Technical Report on CAS

Must be Impaired for a Diagnosis of CAS.

Figure 7

Participants' Responses to Survey Question \#21: "When do you

begin assessment for CAS in a child with autism?".

Figure 8

Speech Characteristics Used to Diagnose CAS in Children with Autism.

Figure 9

Assessment Tools Used to Diagnose CAS in Children with Autism.

Figure 10

Interventions that have been Used for Children with Autism and CAS

Figure 11

Familiarity of Interventions for CAS.

Figure 12

Reported Comfort with Interventions for CAS 
Figure 13

Perceived Benefit of Interventions for CAS when

Used for Children with Autism and CAS ..................................... 53

Figure 14

Interventions for CAS that Participants Report No Knowledge of................ 54

Figure 15

Models Used by SLPs to Implement Treatment for CAS in Children with Autism... 55

Figure 16

How Treatment Methods for CAS in Children with Autism are Selected........... 56 


\section{What is Autism?}

\section{Literature Review}

Autism is a complex neurodevelopmental disorder, resulting in impairments across linguistic, cognitive, and social domains (Wetherby \& Prutting, 1984). Autism is one of a group of disorders, Autism Spectrum Disorder (ASD), which includes autism, Asperger's syndrome, Rett's disorder, childhood integrative disorder, and Pervasive Developmental Disorder-Not Otherwise Specified (PDD-NOS; American Psychiatric Association [APA], 2000). As this is a spectrum disorder, the profiles of individuals with ASD are somewhat heterogeneous. Individuals diagnosed with autism present with qualitative impairments in social interaction and communication, as well as restricted, repetitive or stereotyped behaviors, interests, or activities (APA, 2000). In contrast, individuals with Asperger Syndrome generally do not exhibit significant deficits in language or cognition, but demonstrate social interaction challenges and restricted interests or behaviors (APA, 2000). This paper will focus on children with the specific diagnosis of autism as defined by the APA.

Nonverbal children with autism. Some children with autism do not develop speech as a primary mode of communication. In the late '90s, Prizant (1996) and Seal and Bonvillian (1997) estimated that about half of children with autism fell into the category of nonverbal. However, in recent years the number of children with ASD who remain nonverbal after intervention has decreased. In a 7-year longitudinal study, Anderson and colleagues (2007) found that by age 9, 29\% of 84 children with autism and $10 \%$ of 46 children with PDD-NOS remained nonverbal (i.e. using fewer than five spoken words daily according to the Autism Diagnostic Instrument - Revised [ADI-R]) 
after an initial diagnosis by age 2 . Although this study revealed a decrease in the current percentage of children with ASD who are nonverbal, the results indicate that use of spoken language by children with ASD is still a significant area of need.

\section{Predictors of later expressive language abilities in children with autism.}

Children with autism present with a comprehensive profile of social-pragmatic impairments, all of which have an effect on their level of verbal functioning (Wetherby \& Prutting, 1984). Certain areas of impairment in young children are used in early identification of autism and may be predictive of later verbal language abilities; including gaze shifts, gaze/point following, rate of communication, acts for joint attention and inventory of conventional gestures (Wetherby, Watt, \& Morgan, 2007). Research has suggested that the most reliable predictor for verbal language ability in children with autism is joint attention (Dawson et al., 2004; Mundy, Sigman, \& Kasari, 1990; Sigman \& McGovern, 2005; Tager-Flusberg, Paul, Klin, \& Cohen, 2005). Joint attention refers to "the capacity of infants to coordinate their attention with others in social interactions" (Mundy \& Vaughan, 2007, p.57). A study by Dawson et al. (2004) included 72 3- to 4year -old children with autism, 34 3- to 4-year-old developmentally-delayed (DD) children without autism and 39 2-4-year-old typically-developing children (TD) matched for mental age. The study compared social orienting, joint attention, and attention to another's distress across all participant groups. Joint attention was the most sensitive determinant used to distinguish autism from DD and TD. Joint attention also was most strongly correlated to concurrent language ability. In a longitudinal study that reported on the developmental progress of 48 adolescents with autism who had previously been 
assessed at pre-school and middle-school, Sigman and McGovern (2005) determined that both functional play and joint attention acts in the pre-school years continued to predict gains in language in adolescence.

On tests such as the Bayley Scales of Infant Development (Bayley, 1993) or the Mullen Scales of Early Learning (Mullen, 1995), verbal and nonverbal performance are often correlated in young children with autism (Akshoomoff, 2006; Eaves \& Ho, 2004; Stevens at al, 2000; Tager-Flusberg, Paul, \& Lord, 2005). These findings, together with the evidence from typical development that has demonstrated a correlation between cognitive abilities and speech and language abilities (Prizant, 1996), have led to the assumption that young, nonverbal children with autism frequently have low cognitive functioning. This assumption, combined with the suggestion that young, nonverbal children with autism are nonverbal primarily due to social-communication impairments (Prizant, 1996), has not been questioned, until recently (Teverovsky, Bickel, \& Feldman, 2009; Velleman et al., 2009).

Motor impairments in children with autism. Research has demonstrated that some children with autism may be affected by other impairments that are contributing to the delay or absence of speech. Gross motor (Jansiewicz, Goldberg, Newschaffer, Denckla, Landa, \& Mostofsky, 2006; Rapin, 1996), fine motor (Dziuk, Larson, Apostu, Mhone, Denckla \& Mostofsky, 2007; Nazarali, Glazebrook \& Elliott, 2009; Page \& Boucher, 1998; Seal \& Bonvillion, 1997) and oral-motor impairments (Adams, 1998; Page \& Boucher, 1998) as well as impairments in motor imitation (Nadel \& Aouka, 
2006; Seal \& Bonvillion, 1997) have been well-documented in children with autism.

Findings from some of these studies are presented below.

Gross motor impairments. In a large scale study of children with communication impairments, Rapin (1996) found that 94 of 125 children (75\%) classified as lowfunctioning autism (LFA; i.e. non-verbal IQ less than 80 according to the Stanford-Binet Intelligence Scale: Fourth Edition [Thorndike, Hagen, \& Sattler, 1986] or the Bayley Scales of Infant Development - Mental Scale [Bayley, 1993]) exhibited characteristics of both moderate and severe limb apraxia (defined as: "the inability to imitate movements, manipulate objects appropriately or carry out a complex activity requiring a sequence of motor acts despite adequate comprehension of verbal commands, and lack of a motor deficit..."; pg. 104), while 15 of 51 children (29\%) in the high-functioning autism (HFA; i.e. non-verbal IQ more than or equal to 80 according to the Stanford-Binet Intelligence Scale - Revised or the Bayley Scales of Infant Development - Mental Scale) group exhibited moderate limb apraxia. In comparison with 201 children with developmental language disorder (DLD; 16.9\% of whom exhibited limb apraxia), the HFA group was twice as likely to exhibit limb apraxia, while the LFA group was four times as likely to exhibit limb apraxia. The LFA group was most deficient in the oromotor examination in comparison to all other groups of participants (DLD, HFA, and non-autistic low IQ [NALIQ]), except for drooling in the NALIQ group. No significant relationship was found between oromotor function and general motor skills suggesting that overall deficient motor skills do not result in impaired oromotor function. Lastly, verbal children with autism in both the HFA and LFA group were twice as likely as the NALIQ and three 
times as likely as the DLD group to speak with aberrant prosody (i.e. pitch, rhythm and melody of speech). Overall, results of this study suggest impaired prosody, oromotor skills and gross motor movements in children with autism and, especially, "highlight[s] the need for a more rigorous evaluation of [limb] apraxia in autism" (pg. 119).

Fine motor impairments. Dziuk et al. (2007) conducted a study with 47 children with autism (mean age 10 years, 7 months) and 47 typically-developing (TD) children (mean age 10 years 6 months) to consider the direct association between basic motor skill and praxis (i.e. ability to perform skilled motor tasks) in children with autism. The researchers administered the Physical and Neurological Assessment of Subtle Signs (PANESS; Denckla, 1985), a test of basic motor skill, which examined motor skills such as gait, and timed measures of repetitive and sequential movements of the hands and feet. Researchers also administered an adapted version of the Florida Apraxia Screening Test (Revised), a praxis examination, which assessed purposeful, skilled movements (e.g. gestures on command, imitated gestures and gestures for tool use). When matched for basic motor skill, the autism group showed poorer praxis skills in comparison to the TD group, suggesting that the association between apraxia and autism is not only due to impairments in basic motor skill. Based on study results, Dziuk and colleagues suggested that limb apraxia may be a core feature in a subset of children with autism.

In a study with 12 males with autism and 12 males without autism, Nazarali, Glazebrook, and Elliott (2009) examined situations where the participants were asked to either adjust the hand (i.e. left vs. right hand) or the direction of a planned movement (i.e. moving a hand to the left or to the right), in response to a precue and then a target 
presented 500-1,100 ms later. In instances where the precue was not the same as the target, the tasks required flexibility and reprogramming of the motor plan in order to select the correct (target) response. The participants with autism required more time to adjust the hand than to change the direction of an upcoming movement, suggesting that individuals with autism are engaged in active planning during motor movements; they found it difficult to respond rapidly to prompts to change a previous motor plan. This study provides evidence suggesting impairment in cognitive motor planning rather than impairment in motor skill ability for children with autism.

In a study on sign language and motor skills in children with autism, all 14 of the children with low-functioning autism made formational errors in their signs, particularly hand shape and movement errors (Seal \& Bonvillion, 1997). The errors were correlated with the participants' results on tests of limb apraxia - specifically imitation and purposeful movements. These findings suggest that deficits in motor functioning may account for some of the difficulties these children have when learning to sign, which results in decreased vocabulary, and therefore decreased expressive language.

Oral-motor impairments. Page and Boucher (1998) found high rates of motor impairments, particularly of oromotor (i.e. tongue and lip movements) and manual impairments (i.e. hand skills such as hand shaping and positioning) in a group of 33 children with autism. Significant oromotor impairments were observed in $70 \%$ of the participants, while 55\% exhibited significant manual impairments. Oromotor groping was specifically seen in over one-third of the children. Lastly, although the 7 children with autism in this study, who did not have marked motor impairments, exhibited 
language expression superior to comprehension, only 4 out of the 12 children with both oromotor and manual impairments demonstrated expressive language in advance of comprehension. It is not uncommon for children with autism to exhibit expressive language superior to comprehension (Page \& Boucher, 1998). The difference between expressive language and comprehension abilities (i.e. expressive language was poorer than comprehension) for the majority of the children in this study with oromotor and manual impairments suggests that although their language comprehension should be sufficient to support expressive language, the children still demonstrated poor expressive language skills.

Imitation abilities. Several of the studies mentioned above involved measurements of imitation - a task commonly thought to be impaired in children with autism (Receveur, Lenoir, Desombre, Roux, Barthelemy, \& Malvy, 2005; Rogers, Hepburn, Stackhouse, \& Wehner, 2003). However, Nadel and Aouka (2006) caution that it is important to consider different types of imitation, stating that children with autism may respond better to spontaneous imitation embedded in a meaningful context in comparison to induced imitation of meaningless gestures. Similarly, Williams, Whiten, and Singh (2004) demonstrated that individuals with autism were not impaired when imitating familiar motor tasks, but were significantly impaired when imitating novel motor tasks, which could be a sign of apraxia. Subiaul et al. (2007) hypothesized that children with autism may exhibit impairments in motor imitation due to various motor impairments, and that children with autism may perform differently in a task of cognitive imitation - a task that doesn't require motor learning. They studied 9 participants with 
autism ranging from 8 to 20 years old, and 20 typically-developing 3- and 4-year-olds matched to mental age, as a comparison group. The participants were asked to imitate a simultaneous chaining task on a computer screen. This task involved copying a cognitive rule (e.g. the order in which to select four pictures). The performance of the participants with autism did not statistically differ from the comparison group when copying this novel cognitive rule. These findings suggest that individuals with autism may not have a global novel imitation deficit.

Prosodic impairments in children with autism. Finally, children with autism often exhibit deficits in prosodic production (Schoen, Paul, \& Chawarska, 2009; Shriberg et al., 2001). Schoen, Paul and Chawarska suggest elevated pitch in young children with autism (18-36 months) as well as production of a greater number of complex pitch contours (e.g. pitch fluctuates irregularly within a breath group) during speech in comparison to a typically-developing (TD) group. The TD group more commonly used a flat contour when speaking. Schoen and colleagues speculated that "lack of precise motor control and coordination in the larynx could lead to pitch fluctuations, as laryngeal tension is managed imperfectly" (p. 201). Schoen, Paul and Chawarska also suggested the possibility that vocalizations with such prosodic irregularities may serve more of a self-stimulatory function rather than a communicative function for children with autism (2009).

\section{Motor planning impairments may contribute to deficits in expressive}

language. Prizant (1996) suggested that the occurrence of motor and oral-motor impairments in some children with autism may be contributing to their deficits in 
expressive language. Other research has suggested that motor imitation performance and oral and manual motor skills may predict later expressive and receptive language ability (Gernsbacher, Sauer, Geye, Schweigert, \& Goldsmith, 2008; Stone \& Yoder, 2001). These deficits are not considered more important than the classic social-pragmatic impairments exhibited in children with autism. Instead, oral-motor impairments confound the social-pragmatic impairments; not only do some children appear unmotivated to use expressive language in communication, the physical sequencing of oral movements for speech can also be difficult to coordinate. This difficulty with oral movement sequencing that some children with autism experience may be indicative of a speech motor planning disorder, particularly childhood apraxia of speech.

\section{Evidenced-Based Treatment for Children with Autism}

Over the years there has been a continuing debate in the literature regarding the most effective treatment for children with autism. Treatment goals do, however, remain consistent across approaches - focusing on social and communicative competence (ASHA, 2005). Treatment approaches for autism may be considered along a continuum with structured, behavioral interventions at one end of the continuum and relationshipbased approaches at the other end of the continuum.

Applied Behavior Analysis. On one end of the continuum of treatment are behavioral interventions, which may also be viewed along a continuum of Applied Behavior Analysis (ABA) of most structured to least structured behavioral approaches. ABA involves identifying behaviors that should be extinguished or replaced, behaviors that should be taught and reinforced, reinforcers, and reinforcement schedules. It also 
includes the following guiding principles of behavioral interventions: modeling, prompting, shaping, time delay, reinforcement, and attention to antecedents and consequences to specific behaviors (Ogletree, Oren, \& Fischer, 2007). ABA includes a functional analysis of behavior which aims to identify an antecedent or environmental trigger to a behavior, while describing the behavior and consequences of the behavior (positive or negative). Interventions that have produced significant, lasting results in the reduction of aberrant behavior in individuals with autism have been rooted in principles of $\mathrm{ABA}$ (Foxx, 2008).

Discrete trial-training. At the most structured end of the ABA continuum is discrete trial-training (DTT). DTT is based on Skinner's (1968) operant conditioning model which focuses on positive reinforcement to create behavioral change. DTT follows the traditional components of behavioral therapy (e.g. highly structured, clinician-centered sessions with direct instruction) - consisting of the presentation of a stimulus, a response, and a consequence (Ogletree, Oren, \& Fischer, 2007). However, Delprato (2001) concluded that naturalistic interventions (explained later in this paper) were more effective (as measured by an increased range of language responses) than DTT. This does not mean that DTT is an ineffective treatment method for children for autism. Due to the highly structured sessions, direct instruction and focus on repetition of therapist-selected stimuli, it may be appropriate to use DTT when introducing and teaching acquisition of some language skills.

In one of the original studies incorporating DTT, Lovaas, Koegel, Simmons, and Long (1973) reported on the effects of behavioral therapy with a focus on language for 20 
children with autism, over a period of 7 years. The highly structured behavioral therapy aimed to change behaviors through environmental manipulations (e.g. developing secondary reinforcers and reinforcing desired behaviors and using extinction or contingent aversive stimulation for undesired behaviors). The treatment targeted selfstimulatory behavior, on the basis that a child's self-stimulatory behavior interferes with the child's ability to learn. As a result, inappropriate behaviors (e.g. self-stimulatory, self-destructive and/or tantrum behavior) decreased while appropriate (target) behaviors (e.g. verbal imitation, using speech for meaningful and functional purposes and demonstration of social and self-help skills) increased, spontaneous social interactions occurred for some children, and IQ and social quotients reflected improvement (Lovaas et al., 1973). The results were consistent for all of the children, only to differing degrees.

Naturalistic behavioral interventions. Within the continuum of ABA, naturalistic behavioral interventions tend to be more loosely structured, and often take place in the context of play, utilizing child-selected stimuli, but still involve behavioral principles such as stimulus control, consequences, and motivation (Delprato, 2001). Due to the child-centered structure and play setting, such interventions may be more appropriate for generalization and maintenance of behaviors (Carr \& Kologinsky, 1983).

In a review of the literature on treatments for autism, Rogers and Vismara (2008) cite two significant randomized controlled trials that attempted to replicate Lovaas' original work (Sallows \& Graupner, 2005; Smith, Groen, \& Wynn, 2000). Sallows and Graupner (2005) conducted a study using the intensive behavioral treatment described by Lovaas, except that they did not use aversives. Treatment also incorporated Pivotal 
Response Training (PRT; Koegel, Koegel, Harrower, \& Carter, 1999), augmentative communication (e.g. a picture system), and emphasized play and motivation. The approach used in this study falls on the other end of the ABA continuum from Lovaas' original work in 1973; while it still incorporated behavioral principles, the treatment sessions were less structured and more child-centered. The study involved two groups of participants with an average age of 35 to 37 months at the beginning of treatment. One group $(n=13)$ received clinic-directed intervention (e.g. 6 to 10 hours of in-home supervision from a senior therapist with 40 hours per week of 1:1 treatment from trained therapists) while the other group $(n=10)$ received parent-directed intervention (e.g. 6 hours per month of in-home supervision from a senior therapist and consultation every 2 months with the number of weekly treatment hours chosen by the parents; the average in year 1 was 32 hours, year 2 was 31 hours). The parent-directed intervention was intended to be a less intensive treatment. Similar to Lovaas' findings, significant improvement (i.e. achieved Full Scale IQs in the average range and showed increases in language and adaptive areas) was seen in almost half (48\%) of the children (including children from both treatment groups). At age 7, the same children were succeeding in regular classrooms with average academic abilities, fluent speech and consistent peer relationships. In addition to the implications for improvement in IQ, language, and adaptive areas, the evidence from this study also supports the use of parent-directed intervention.

In 2000, Smith et al. conducted a similar study comparing intensive, but less structured ABA treatment $(\mathrm{n}=15)$ and parent training $(\mathrm{n}=13)$. The treatment groups 
included young children with autism and PDD-NOS. Results replicated those from Lovaas' study in some of the children from the intensive treatment condition who showed an increase in IQ, visual-spatial ability, language, and academic achievement. However, this study did not replicate the same gains originally reported by Lovaas (e.g. neither children from the intensive treatment group nor the parent training group improved on standardized tests of adaptive functioning or behavior problems).

Since Lovaas' work in the 1970s, ABA approaches continue to be the most research-based interventions for children with autism (Delprato, 2001; Erba, 2000; Lovaas \& Smith, 1989; Prizant \& Wetherby, 1988; Smith, 2008). Though the principles of ABA have remained constant, treatment approaches for children with autism are now more comprehensive, targeting the full range of impairments observed in children with autism (e.g. qualitative impairments in social interaction and communication together with repetitive or stereotyped behaviors and interests) and occurring in more natural contexts (e.g. during play and with child-selected materials), aiming for generalization and maintenance of learned behaviors. It is suggested that a comprehensive and individualized treatment approach which utilizes more than one model will be most effective for children with autism (Goldstein, 2002; Ogletree, Oren, and Fischer, 2007; Rogers \& Vismara, 2008).

Comprehensive early intervention programs. Several evidence-based, comprehensive early intervention treatments are currently being implemented for young children with autism. Some of the approaches that follow the naturalistic behavioral model along the treatment continuum are: Learning Experiences...An Alternative 
Program for Preschoolers and Parents (LEAP; Hoyson, Jamieson, \& Strain, 1984), Treatment and Education of Autistic and Related Communication Handicapped Children (TEACCH; Mesibov, 1996), and The Early Start Denver Model (ESDM; Dawson et al., 2010). Floortime (Greenspan \& Wieder, 1998) is a relationship-based approach, present at the other end of the autism treatment continuum. These treatments are described below.

LEAP (Hoyson, Jamieson, \& Strain, 1984) targets social interactions using both ABA teaching techniques in an inclusion classroom with parent participation. Strain and Hoyson (2000) reported on follow-up outcomes for the first 6 children who were involved in the initial LEAP research protocol (Hoyson, Jamieson, \& Strain, 1984). The children ranged from $2 \frac{1}{2} 2$ yrs to 4 yrs 5 months at the beginning of treatment. Results at exit (after 2 years of treatment) and age 10 demonstrate developmental growth across all domains of performance. At exit and at age 10, children presented with reduced autism scores on the Childhood Autism Rating Scale (CARS; Schopler, Reichler, \& Renner, 1988), an increase in appropriate behavior (e.g. follow adult requests, be actively and appropriately engaged, and not exhibit any stereotypic, ritualistic behavior), an increase in IQ on the Stanford-Binet Intelligence Scale (Thorndike, Hagen, \& Sattler, 1986) and an increase in positive social interactions. 5 of the 6 children spent their school careers in regular education classrooms without special education services.

TEACCH (Mesibov, 1996) follows a developmental framework with increased structure and task-analyzed goals, building off of the strengths of children with autism while focusing on lifelong continuum of services through community and families. 
Aldred, Green, and Adams (2004) conducted a study with 28 children with autism, ages 2 through 5 years, using the TEACCH model together with a parent-training program. The results of Aldred et al.'s study revealed reduced autism severity scores, increased expressive vocabulary and increased child communication with parents.

ESDM (Smith, Rogers, \& Dawson, 2008) is a developmental, social interactionbased intervention that is rooted in the principles of applied behavior analysis, particularly PRT. ESDM focuses on early intervention with toddlers with ASD, beginning as early as 12 months of age; the comprehensive intervention is based on the Denver Model (Rogers, Hall, Osaki, Reaven, \& Herbison, 2000), which was originally designed as a center-based intervention for preschool-age children (see further discussion of the Denver Model below). In a randomized control trial of ESDM with toddlers from 18-24 months, Dawson and colleagues (2010) found that children in the ESDM group demonstrated significant improvements in IQ, adaptive behavior and diagnostic status after 2 years of intensive intervention as compared to a control group that was receiving community-based early intervention services.

Floortime (Greenspan \& Wieder, 1998), a relationship-based intervention (on the other end of the broader autism intervention continuum from $\mathrm{ABA}$ interventions), emphasizes the importance of building relationships in a child-directed play model. The goal of floortime is "to establish secure relationships in order to foster development" (Erba, 2000, pg. 87). Out of 200 children who received 2 or more years of floortime intervention, Greenspan and Wieder (1997) found that $58 \%$ of the children fell into the category of good-to-outstanding (e.g. showing spontaneous symbolic abilities related to 
intent and affect, able to engage in purposeful and organized problem solving and developed multiple relationships). This group also scored out of the range for autism on the Childhood Autism Rating Scale.

The treatment models described in this paper include many of the principles suggested in 2001 by the National Research Council (NRC; as cited in Ogletree, Oren, \& Fischer, 2007) as priorities when working with children with autism. Priorities suggested by the NRC include: early intervention (by age 2); intensive instruction (25 or more hours per week) starting at 24 months of age; repeated, planned teaching opportunities; systematic, developmentally appropriate instruction; family inclusion; ongoing assessment; and instruction in settings with typical peers. Including these principles as part of any comprehensive treatment program designed for children with autism would likely be best practices in treatment.

\section{Treatment of Speech Sound Disorders in Children with Autism}

For children with autism who also have a speech sound disorder, speech production goals should become part of a comprehensive treatment program. A recent study by Rogers et al. (2006) has begun to look at treatment originally designed to target adult apraxia of speech as a treatment for nonverbal children with autism: PROMPT (Prompts for Restructuring Oral Muscular Phonetic Targets) combined with the Denver Model (described in Rogers et al., 2000). PROMPT, which utilizes auditory and tactile cues, together with physical manipulation of the speech mechanism, has been effective in treatments for adult apraxia of speech (Freed, Marshall, \& Frazier, 1997; Square, Goshulak, Bose, \& Hayden, 2000 as cited in Rogers et al., 2006). The Denver Model is a 
developmental approach to treatment for autism. The study involved 10 nonverbal (i.e. spontaneous use of less than five functional words per day) children with autism, ages 20-65 months. None of the children were reported to have a diagnosis of apraxia. The use of PROMPT together with the Denver Model resulted in improved spontaneous speech (i.e. using five or more novel, functional words spontaneously and spoke multiple times per hour) for 8 out of the 10 children involved in the 2006 study by Rogers et al. Their study is an introduction to the idea that treatment models targeting motor speech disorders in children with autism can be an effective addition to an overall comprehensive treatment approach for autism.

Precision teaching has also been introduced as a possible approach to treating speech sound disorders in children with autism. Precision teaching focuses on timebased mastery criteria (e.g. a certain number of correct responses per minute) instead of accuracy-based mastery (e.g. 80\% correct; Binder, 1988). Other key concepts include daily practice and timed measurements as well as using a graph to chart progress daily. Fabrizio, Pahl, and Moors (2002) reported on the use of precision teaching for articulation with a 7-year-old boy with autism in a chart share. The boy also attended a self-contained classroom in a public school and received in-home intervention 4-6 days per week for 3 hours per day. Treatment targeted correct production of $/ \mathrm{b} /$ and $/ \mathrm{v} /$ as it was reported that his intelligibility was affected by the incorrect use of these two phonemes. After 12 weeks of practice, timings, and gradual shaping of the skills (i.e. treatment first targeted /v/ in isolation, then moved to words with /b/ and /v/ in final position and finally words with /v/ and /b/ in all positions), the boy's final frequency 
count in the last phase was 100 correct responses per minute with no errors (he began the last phase with 40 correct responses per minute with 2 errors). The family also reported significant improvement in intelligibility after this. The two studies presented here (Rogers et al., 2006; Fabrizio, Pahl, \& Moors, 2002) suggest that treatment targeting correct speech production can be an effective part of a comprehensive treatment approach for children with autism. However, the literature is lacking in the area of treatment for motor speech disorders in children with autism; "evidence-based treatment studies to explore the efficacy of various motor speech treatment approaches for [children with autism] are sorely needed" (Velleman, 2009, p. 44).

Interventions that target verbal production. Treatment models for low verbal or non-verbal children with autism that target verbal productions, but not necessarily a motor speech deficit, have also been proposed in the literature. One of the most common initial steps in eliciting vocalizations from children with autism is to teach them to independently request items (i.e., mand) (Drash, High, \& Tudor, 1999; Williams \& Greer, 1993). Manding is a technique often used with children with autism to generate motivation for communication. However, a child must first establish a vocal repertoire in order to use vocalizations to make requests. Ross and Greer (2003) suggested a technique known as generalized imitation in order to establish vocal imitation skills. This technique utilizes rapid gross (e.g. clapping hands) and fine motor (e.g. touching nose) imitation as an antecedent to the imitation of vocalizations used to mand. All 5 of the participants (nonvocal children with autism) in the Ross and Greer (2003) study were able to imitate vocal mands through the use of rapid motor imitation. The results were 
maintained for 4 of the 5 participants. Although this treatment model does not explicitly target a deficit in motor speech, it utilizes motor imitation as a technique to successfully elicit vocalizations.

Melodic Intonation Therapy (MIT) has also been suggested as an alternative method of teaching speech to nonverbal children with autism (Miller \& Toca, 1979). To the author's knowledge, the 1979 study by Miller and Toca is the only study on MIT for children with autism. In this study, intoned utterances were paired with signed gestures to facilitate verbal responses from a nonverbal 3-year-old boy with autism. Highly motivating rewards paired with continuous modeling of both the intoned utterance and the signed gesture resulted in independent verbal requests after 25 sessions. For this child, motivation, together with intensive, consistent modeling resulted in the beginning of verbal communication.

Interventions that target intentional, nonverbal communication. Researchers have also recognized that in order for verbal language intervention to be effective for low verbal or non-verbal children with autism, treatment must first address intentional, nonverbal communication and varied object play (Yoder \& McDuffie, 2006). Several naturalistic language interventions use play and access to objects in order to elicit language from children who do not use intentional speech (e.g. Pivotal Response Training [PRT], Koegel, et al, 1999 and Enhanced Milieu Teaching [EMT], Hancock \& Kaiser, 2002; Kaiser, Hancock, \& Nietfeld, 2000). EMT utilizes responsive engagement in which children are engaged in activities that interest them while the adult embeds prompting into the play interaction (Hancock \& Kaiser, 2002). EMT has been effective 
in increasing early communication abilities in children with autism, both when implemented by trained parents (Kaiser et al, 2000) and when implemented by trained therapists (Hancock \& Kaiser, 2002). PRT focuses on learning across the child's environment, through the use of pivotal areas, that is, areas that, when targeted, lead to change in other, untargeted areas (Koegel et al, 1999). Koegel and colleagues identified areas such as response to multiple cues, motivation, self-management, and self-initiations as pivotal areas. Motivational procedures (e.g. requiring that the child produce a vocalization in order to receive a desired item) are especially effective in acquiring verbal language for nonverbal children with autism (Koegel, Sze, Mossman, Koegel, \& Brookman-Frazee, 2006).

\section{What is Childhood Apraxia of Speech?}

According to the American Speech and Hearing Association (ASHA), childhood apraxia of speech (CAS; previously known by a variety of terms, including verbal dyspraxia and developmental apraxia of speech), is defined as "a neurological childhood speech sound disorder in which the precision and consistency of movements underlying speech are impaired in the absence of neuromuscular deficits (e.g., abnormal reflexes, abnormal tone)" (ASHA, 2007a, p. 1). The primary impairment in CAS is the planning and sequencing of the specific movements involved in speech. This impairment results in errors in speech sound production and prosody (ASHA, 2007b).

Currently, a definitive list of diagnostic features of CAS does not exist; nor is there one specific characteristic that must be present in order to make a diagnosis. Review of the literature, however, can help determine a common list of features 
associated with CAS. According to ASHA's technical statement on CAS, three specific areas of deficit have been frequently highlighted throughout the research literature: (1) inconsistent error production on both consonants and vowels; (2) lengthened and impaired co-articulatory transitions between sounds and syllables; and (3) inappropriate prosody (2007b). Other common characteristics cited in the literature include: limited consonant and vowel phonemic repertoire; inconsistent production of complex word shapes; suprasegmental differences; oral-motor groping, or searching for the motor movements needed to produce some or all phonemes; inability to produce a speech sound or sequence that has previously been produced correctly; deviant or delayed speech development; inability to produce sounds in diadochokinetic tasks (most notably on sequencing motion rates [SMR]); increased errors with increasing utterance length; variability in error productions over time; and development of their own gesture system, often accompanied by non-speech "noises." (Davis, Jakielski, \& Marquardt, 1998; Hall, 2000; Marquardt, Jacks, \& Davis, 2004; Murdoch, Porter, Younger, \& Ozanne, 1984; Thoonen, Maassen, \& Wit, 1996;).

Impaired prosody in children with CAS. Odell and Shriberg (2000) conducted a study with 14 children with suspected CAS to examine prosody-voice characteristics. All 14 of these children were identified as exhibiting inappropriate stress. For 10 of 14 children, this was demonstrated by the use of excessive-equal stress; neither rate nor phrasing errors occurred consistently. These findings strengthened the results of an earlier study by Velleman and Shriberg (1999), in which 15 children with apraxia of speech presented with robotic sequential stress and patterns of syllable omission. 
Limb and oral apraxia in CAS. Children with CAS commonly exhibit impairments in non-speech motor movements; limb, oral, and verbal apraxia often occur together in children (Dewey, Roy, Square-Storer, \& Hayden, 1988; Newmeyer et al., 2007). The 4 children with verbal apraxia in the study conducted by Dewey and colleagues scored significantly lower on the limb praxis subtests in comparison to the control group $(\mathrm{n}=4)$ and the group of children with an unidentified speech sound disorder $(n=5)$. Both groups of children with speech sound disorders exhibited a deficit in oral gestures. Kornse, Manni, Rubenstein and Graziani (1981) found that manual dexterity of both the right and left hands (measured by tasks that involved inserting and removing pegs from a pegboard) was impaired in all 18 of the participants with developmental apraxia of speech, when compared with typically developing, age-matched peers.

\section{What is the treatment for CAS?}

Current evidence-based practice on the treatment of CAS highlights the importance of intensive practice, application of motor learning principles, use of visual cues, early introduction of self-monitoring, and attention to stress production (ASHA, 2007b). These treatment factors are fundamental in integral stimulation, a treatment approach for apraxia of speech incorporating the principles of motor learning (e.g. specific and repeated practice of targets, knowledge of results (frequency and specificity of feedback), and conditions of practice (blocked vs. random); Strand \& Skinder, 1999). Integral stimulation was originally developed for adults with apraxia of speech. In its purest form, it involves the use of these three tenets: "Watch me, listen to me, and say it with me," and the process of a clinician shaping the client's responses by adding or 
fading auditory and visual cues (Rosenbek, Lemme, Ahern, Harris, \& Wertz, 1973). Integral stimulation was more recently modified for children with CAS by adding in continuous shaping of the movement gesture (Davis \& Velleman, 2000; Strand \& Debertine, 2000).

In a treatment efficacy study utilizing integral stimulation with a 5-year-old girl, Strand and Debertine (2000) cited the importance of distributed practice (e.g. more practice sessions for shorter periods of time) compared with massed practice (e.g. fewer practice sessions for longer periods of time). The intervention strategy was implemented four times per week; improvements in articulatory performance were credited to this repetitive practice, also important in motor learning (Strand \& Skinder, 1999). Improvements were also credited to the selection of highly functional phrases as well as limiting the number of stimuli to 5 (allowing for repetitive practice for accuracy while maintaining distributed practice for motor learning). A study with two children with suspected CAS by Edeal and Gildersleeve-Neumann (2010) also noted the importance of frequent and intense practice of speech sounds for faster acquisition of targets and generalization to untrained words.

Dynamic Temporal and Tactile Cueing. Other treatment approaches utilizing principles similar to those observed in integral stimulation have been used successfully with children with CAS. Strand, Stoeckel and Baas (2006) implemented an approach based on integral stimulation with 4 children with apraxia of speech - dynamic temporal and tactile cueing (DTTC), a treatment similar to PROMPT. DTTC is also based on the principles of motor learning and involves the clinician physically helping the child form 
necessary jaw and lip configurations during simultaneous production. The clinician then fades the simultaneous production, using tactile and gestural cues to prompt the child to form correct sound configurations. Initial maximum support contributes to accuracy and success. During DTTC, the child is asked to slow down and maintain articulatory configurations for a longer duration than is typical, providing additional proprioceptive feedback during speech. 3 out of the 4 children, all of whom were essentially nonverbal at the start of the study, showed rapid change. In an attempt to maximize the principle of distributed practice, the children in this study were seen twice per day, 5 days per week, for half hour sessions. Overall, the principles of motor learning, including intensive practice are thought to be essential in the treatment of CAS.

Alternative treatment approaches for CAS. Some alternative treatment approaches for CAS are suggested in the literature. Melodic Intonation Therapy (MIT) has been proposed as an effective treatment method by Helfrich-Miller (1983). MIT involves intoning targeted utterances so that the tempo is lengthened, the rhythm and stress are exaggerated, and the pitch is reduced into a consistent pattern (Helfrich-Miller, 1994). In 1983, Helfrich-Miller studied 2 children with CAS who both made substantial improvements in articulation and phonemic sequencing with the use of MIT. Alternative and Augmentative Communication (AAC) has also been effective for some children with CAS (Cumley \& Swanson, 1999). Cumley and Swanson conducted case studies with 3 children with CAS. Both low-technology aids (i.e., context-specific communication boards, remnant books, and symbol dictionaries) and high-technology aids (i.e., voice output communication aids and print output communication aids) were introduced to 
these children to support their natural speech. Combined with articulation treatment, the AAC aids and strategies created more opportunities for successful communication and supported their natural speech by allowing the children to initiate, participate in, and repair breakdowns in conversations both in the home and school environments. Parents and teachers of all 3 children reported improvements in communication and decreases in negative behaviors, with the opportunity to communicate using AAC. AAC may be a good option if traditional articulation therapy for CAS is not successful.

Davis and Velleman (2000) have suggested adding sequenced play to the intervention program, especially for young children with CAS. Building sequencing into play can be less demanding on the child and, in the beginning, may not even require oral communication from the child. Later, the sequence of play may be paired with speech sound sequences. This allows for sequencing and speech sound practice even before the child is required to use speech as a mode of communication in intervention. A similar approach that does not require oral communication in the beginning may be beneficial for children with autism, especially those who are nonverbal.

\section{The Current Study}

The occurrence of similar speech and non-speech behaviors in some children with autism and CAS calls for the consideration of CAS in some children with autism. However, the majority of research on CAS has been conducted with children who are otherwise typically developing. Research is just beginning to consider the possibility of CAS occurring in children with other developmental disorders (Kumin, 2006; Teverovsky et al., 2009). Teverovsky, Bickel and Feldman studied the functional 
characteristics of children with CAS ( $\mathrm{n}=201$ ), according to the International

Classification of Functioning, Children and Youth version (ICF-CY). In addition to discovering functional impairments (e.g. attention, vestibular function, temperament, and learning to write), over half of the children also had co-occurring health, mental health, and developmental conditions, including autism. In a survey of parents of children with Down Syndrome, 15\% of the children whose parents responded to the survey had been diagnosed with CAS, but many more children showed clinical symptoms of CAS (Kumin, 2006). It is evident that CAS may be affecting the intelligibility of children with developmental disorders, in addition to children who are otherwise typically-developing. There is a paucity of research regarding the possibility of CAS occurring in children with other developmental disabilities. This study will therefore examine the occurrence of CAS in children with autism.

It will be important to consider alternative treatment methods if it is found that some children with autism are being identified with CAS - a motor speech disorder that is traditionally treated differently than autism. It is also important to consider that some nonverbal and low verbal children with autism may benefit from treatment for a motor speech disorder as part of a comprehensive treatment program; it should not be assumed that oral communication is not possible for these children (Velleman et al., 2009).

Purpose of the current study. The purpose of the present study was to determine whether and to what extent children with autism are being diagnosed with or suspected to have CAS and what assessment and treatment methods are currently being used with these children. This was accomplished by conducting a survey of speech- 
language pathologists (SLPs). For those SLPs who are serving children with autism and suspected or diagnosed CAS, the survey also inquired about: (a) the criteria (speech characteristics) used to identify CAS in children with autism, and (b) the treatment method/procedures that are being used in intervention. Lastly, the survey addressed the possibility of CAS that is misdiagnosed or not diagnosed and why this may occur in children with autism.

A survey has allowed us to discover the prevalence of suspected CAS in children with autism. It has also provided information on how and why SLPs are diagnosing these children this way. The survey was sent to SLPs working with children in birth to three and preschool settings as this would give information on chronological age of identification as well as level of expressive language considered necessary for a diagnosis CAS. After it was discovered that SLPs are seeing some children with autism and CAS, it became important to understand what treatment approaches are currently being used with the population. The results of the survey also provided information on which approaches are currently in practice and how SLPs are deciding on treatment methodologies. The findings of the survey have demonstrated the need for the development of diagnostic and treatment guidelines for CAS in children with autism.

The specific research questions for this study were: how many SLPs are currently diagnosing or suspecting CAS in children with autism? Which assessment and treatment methods are currently being used for these children? 


\section{Participants}

\section{Method}

The population of interest for this study consisted of SLPs working with children in early intervention and/or preschool settings. These populations were chosen as it is generally accepted that both autism and CAS are identified during these early years. Survey questions helped to further classify the SLPs who completed the survey (e.g. specific work setting and urban vs. rural settings).

All participants received an e-mail with a link to the survey explaining the purpose of the survey and why they were receiving the e-mail (Appendices A-C). After the participants clicked on the link to the survey, but before they began the survey, a message was displayed that explained the study had been approved by the Institutional Review Board at Portland State University. The message also provided information about being a research participant. By clicking "Click to next page" the participants acknowledged that they read and understood the information provided and that they agreed to take part in the study. This message is shown at the beginning of the survey in Appendix D.

\section{Survey}

A survey on CAS and autism was developed based on a review of the literature. The survey had three parts. Part 1 consisted of 15 questions on the demographic information of the participants. Part 1 included questions regarding the number of children they serve or assess per month, how many of those have a DSM-IV diagnosis of autism, how many of those are nonverbal and how many are suspected to have CAS. 
Part 2 had 12 questions and addressed the assessment and diagnostic procedures used to identify CAS in children with autism. Assessment procedures were taken from ASHA's technical report on CAS (2007b). Part 2 also included diagnostic criteria addressing the major speech and oral motor characteristics typical of children with CAS (ASHA, 2007b), (e.g. inconsistent production of speech sounds; limited speech sound repertoire; groping; decrease in intelligibility with increasing linguistic complexity; slow progress in treatment; difficulty combining and sequencing phonemes; difficulty with imitation; omitting sounds and syllables in speech; difficulty producing novel words; inappropriate prosody). Items in part 2 also addressed signs of limb and oral apraxia, and weakness or paralysis of the speech mechanism. Weakness or paralysis is suggestive of dysarthria, not CAS, thus the results of the survey will reveal if, in some cases, CAS is being misdiagnosed (Velleman et al., 2009). A "checklist" format was used together with options to expand or explain answers as needed for part 2 of the questionnaire.

Part 3 had four questions that addressed treatment techniques and decisions. Part 3 consisted of a checklist together with an option to fill in answers not otherwise specified. Questions focused on types of treatment currently in practice as well as how SLPs are selecting and implementing the treatment. The complete survey is given in Appendix D.

The survey was sent as a link in an email to SLPs who are certified by the American Speech and Hearing Association (ASHA), and who are affiliates of the following ASHA Special Interest Divisions: Special Interest Division 1: Language Learning and Education; Special Interest Division 2: Neurophysiology and Neurogenic 
Speech and Language Disorders; and Special Interest Division 16: School-Based Issues. A link to the survey with a brief message (See Appendix B) was also posted on the discussion board of the following Facebook pages: American Speech and Hearing Association; Apraxia- Kids; and Autism Society of America. It was also sent to the email distribution lists for the Apraxia-Kids organization. Lastly, snowball sampling was used, beginning with SLPs associated with Portland State University who were asked to complete the survey and forward the e-mail with a link to the survey to other SLPs who they knew and so on. This letter is in Appendix C. Snowball sampling can be an effective sampling technique when the target population is difficult to access, such as in this study. The hope was that the use of the above sampling methods would yield a large enough sample to determine the breadth of occurrence of CAS in children with autism and current treatment methodologies used throughout the United States.

\section{Procedures}

Once the survey was developed, a pretest was administered to three practicing SLPs to make sure that the questions were clear, that the survey addressed the issue of diagnosing CAS in children with autism, and encouraged nonbiased responses (Dillman, 2000). In addition, the pretest determined the duration. The researcher sat with the SLP as they completed the survey and asked them to "think out loud" as they read and answered the survey questions. If the SLP reacted to or answered a question unexpectedly, the researcher asked the SLP to explain their thinking process as they answered the question and asked for suggestions to increase the clarity of the question. Changes were made based on feedback from the SLPs. 
After the questionnaire was finalized, it was posted online at surveygizmo.com. An e-mail was sent to the participants requesting their participation together with an explanation of the purpose for this study. The email requested that surveys be completed within 4 weeks. The survey concluded with a "thank you" letter written by the researcher, thanking the participants for their time and contribution to this area of research (see the message at the end of the survey in Appendix D). The researcher's email address was included in the "thank you" letter if participants chose to request a summary of unanalyzed results after the completion of the survey.

\section{Data Analysis}

Survey responses were stored online at surveygizmo.com. The responses were password-protected, accessible only by the researcher and her advisor, Dr. Christina Gildersleeve-Neumann.

Part 1. Results from Part 1 of the survey (Demographic Information) were analyzed with descriptive statistics to determine the mean and standard deviation for level of education attained, years working as an SLP in their current setting and caseload sizes. Responses to question \# 4 ("In what state do you currently work?"), \#5 ("What population do you currently serve?"), \# 6 (“What is your current work setting?”) and \# 8 ("Do you work in an urban or rural area?") were analyzed with descriptive statistics to determine the distribution of responses from across the country. Responses to question \# 7 (“Who do you collaborate with?") provided data on the average number of professionals the participants collaborated with, particularly if they collaborated with an autism specialist or other professional who may work specifically with children with 
autism (e.g. Psychologist, Applied Behavior Analyst, Developmental Pediatrician or Gastroenterologist).

An average percentage of total children served who have autism, and an average percentage of children with autism who are suspected to have CAS per caseload was determined. These averages revealed if children were being identified with autism and CAS and if some SLPs appear to be identifying and serving proportionately more children with these conditions than others. Lastly, this section of the survey provided information on the average percentage of children with autism and suspected CAS who are also considered to be nonverbal.

Part 2. Results from Part 2 (Diagnostic Criteria) of the survey were analyzed with descriptive statistics to determine how often SLPs are the professionals who are making the diagnosis of CAS and if SLPs who do not make the original diagnosis are confirming the diagnosis. Results from Part 2 were grouped to reflect which assessment tools are most often used to identify CAS in children with autism as well as which speech characteristics are most commonly observed. This section of the survey also included four questions on the characteristics of both autism and CAS. The answers to these questions (ratings on a 5-point Likert scale) reflected the participants' knowledge of autism and CAS.

Part 3. Results from Part 3 (Intervention) were analyzed with descriptive statistics to determine which treatment techniques were most commonly used to target speech production as well as how SLPs are selecting which treatment techniques to use with these children. Results from question \#28 revealed what percentage of respondents 
have implemented, are familiar with, are comfortable with, have seen benefit from or have no knowledge of specific treatment approaches for children with autism and CAS. Responses were compared to best practices outlined for these populations, which were presented previously in this paper. Responses also revealed if treatments for CAS were being integrated as part of a comprehensive treatment approach to autism, if they were being used in isolation, or if they were used at all for children with autism and suspected CAS. 


\section{Results}

\section{Participant Demographics}

132 surveys were received and analyzed; 113 participants answered all questions - the remaining participants either left the survey part-way through or did not answer all 31 survey questions. Responses from partial surveys were analyzed only for the questions answered. SLPs from across the United States working with children aged birth to 6 completed the survey. See Figure 1 for the geographic distribution of participants by U.S. region. Table 1 shows the distribution of participants by state.

All participants served children who were at least 0- to 6-years old. Although some participants also served older children, answers to survey questions were based on the children they served who were 0 - to 6-years old. $86 \%$ of participants served children ages 4-6 years and 77\% reported serving children from birth to 3-years old; many served children in both categories.

SLPs working in both urban and rural areas participated in the survey. Of the total number of participants, $75 \%$ reported working in an urban area and $25 \%$ reported working in a rural area. 


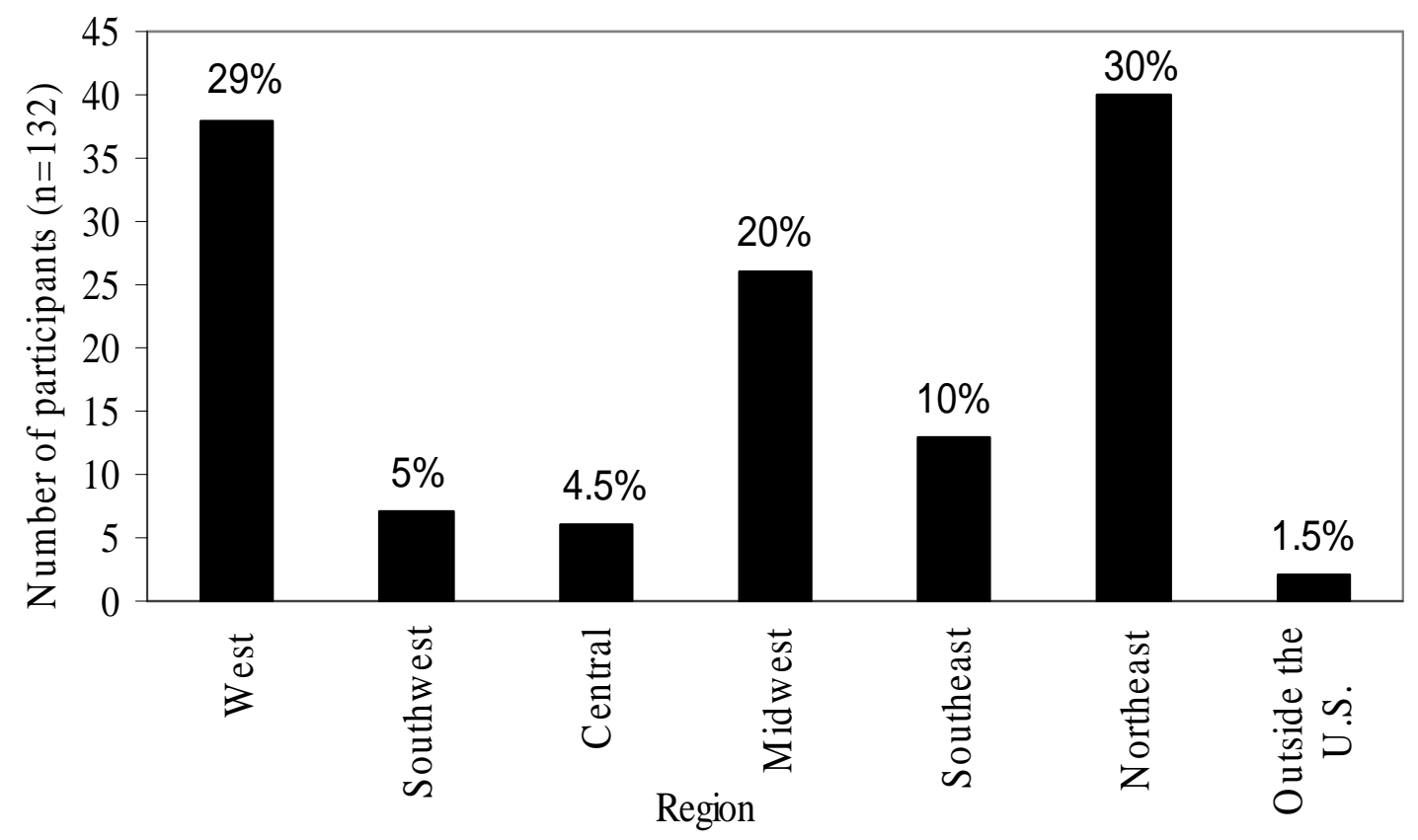

Figure 1. Distribution of Participants by Region 
Table 1

Distribution of Participants by Region and State

\begin{tabular}{|c|c|c|c|c|c|c|c|}
\hline Region & $n$ & State & $n$ & Region & $n$ & State & $n$ \\
\hline \multirow{5}{*}{ West } & 38 & Oregon & 23 & Southeast & 13 & North Carolina & 7 \\
\hline & & Washington & 3 & & & Alabama & 2 \\
\hline & & California & 10 & & & Kentucky & 2 \\
\hline & & Arizona & 1 & & & Florida & 1 \\
\hline & & Idaho & 1 & & & Georgia & 1 \\
\hline \multirow[t]{4}{*}{ Central } & 6 & Kansas & 3 & Northeast & 40 & Massachusetts & 11 \\
\hline & & Missouri & 1 & & & New York & 6 \\
\hline & & Nebraska & 1 & & & Connecticut & 5 \\
\hline & & South Dakota & 1 & & & District of Columbia & 3 \\
\hline \multirow[t]{2}{*}{ Southwest } & 7 & Texas & 4 & & & New Hampshire & 3 \\
\hline & & Louisiana & 3 & & & New Jersey & 3 \\
\hline \multirow[t]{6}{*}{ Midwest } & 26 & Illinois & 9 & & & Pennsylvania & 3 \\
\hline & & Minnesota & 8 & & & Maryland & 2 \\
\hline & & Michigan & 3 & & & Vermont & 1 \\
\hline & & Ohio & 3 & & & & \\
\hline & & Wisconsin & 2 & Outside & & & \\
\hline & & Indiana & 1 & the U.S. & 2 & & \\
\hline
\end{tabular}

Participants represented a wide range of experience levels in the field of speechlanguage pathology. The average number of years as a certified SLP was 11 to 15 and the average number of years working in their current setting was 6 to 10 . There were 124 participants who had obtained at least one bachelor's degree; of these, $65 \%$ obtained a bachelor's degree in the field of speech-language pathology. The average year of graduation for a bachelor's degree was 1989 (with a range from 1961 to 2007). Out of 
the 132 participants, 130 indicated obtaining at least one Master's degree; of these, 93\% were in the field of speech-language pathology. For a master's degree, the average year of graduation was 1994 (with a range from 1970 to 2009).

Of the total participants, $13 \%$ indicated obtaining a Ph.D. A high proportion of these, $71 \%$, were in the field of speech-language pathology. Other Ph.D. fields included linguistics, infant mental health, therapeutic science, special education, and behavioral science. The average year of graduation for a Ph.D. was 1996 (with a range from 1980 to present).

Participants reported a wide variety of work settings and were fairly evenly distributed across settings. The top two work settings reported were private practice $(28 \%)$ and county/state early intervention services (26\%). Figure 2 displays the distribution of participants' work settings.

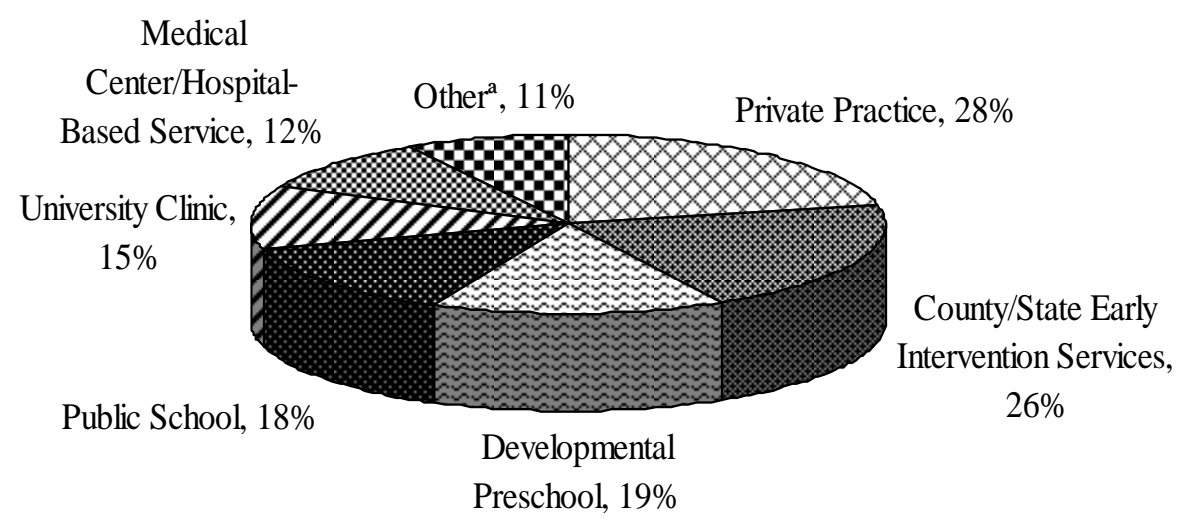

Figure 2. Distribution of participants across work settings.

${ }^{a}$ Birth-to-three center, Non-profit/Community-based, Home, Rehab Center, Child Care

Setting, Early Intervention Independent Contractor; Education service center. 
It is common for SLPs to collaborate with other professionals and/or to work on a team with those professionals. The vast majority of participants (130) reported collaborating with at least one other professional. On average, participants reported that they collaborate with six other professionals. Table 2 lists the professionals that participants collaborated with; the top three professions were Occupational Therapy (88\%), Special Education (81\%), and Physical Therapy (72\%).

Table 2

Other professionals who participants report collaborating with.

\begin{tabular}{lcc}
\hline \multicolumn{1}{c}{ Professional } & $n$ & $\%$ of participants \\
\hline Occupational Therapist & 114 & $88 \%$ \\
Special Educator & 105 & $81 \%$ \\
Physical Therapist & 93 & $72 \%$ \\
Psychologist & 81 & $62 \%$ \\
General Educator & 67 & $52 \%$ \\
Audiologist & 60 & $46 \%$ \\
Autism Specialist & 57 & $44 \%$ \\
Developmental Pediatrician & 52 & $40 \%$ \\
Applied Behavior Analyst/ Behaviorist & 40 & $31 \%$ \\
Neurologist & 31 & $24 \%$ \\
Family Resource Specialist & 22 & $17 \%$ \\
Gastroenterologist & 13 & $10 \%$ \\
Other & & $34 \%$ \\
None & 44 & $2 \%$ \\
aparents/family, nurse, other SLPs, hearing specialist, social worker, \\
$\begin{array}{l}\text { augmentative communication specialist, dietician, vision specialist, } \\
\text { nutritionist, developmental therapist, educational diagnostician, music } \\
\text { therapist, ENT, sleep disorders specialist, and Floortime providers. }\end{array}$
\end{tabular}




\section{Total Numbers of Children Served by Participants}

The average number of children served within the ages of birth to 6 was 28 children with a standard deviation of 28 and a range of 0 to 300 . Due to the outlier of 300 , the average and standard deviation are positively skewed. When the outlier was taken out of the calculation for average number of children served, the number changed to 26 children served with a standard deviation of 15 and a range of 0 to 60 . The mean number of children with autism currently served per participant was 5.89 children and the mean number of children with autism and suspected CAS per participant was 1.08.

\section{Characteristics of Children with Autism Served by Participants}

Table 3 shows the total number of children served across all participants, and the mean number of children per participant for each population of interest in this study (i.e. children with autism, children with autism who are nonverbal, children with autism who have a speech sound disorder, children with autism and suspected apraxia of speech, children with autism and diagnosed apraxia of speech, and children with autism and suspected apraxia of speech who are nonverbal. 
Table 3

Total number of children from all responses for each population of interest and mean number of children served per participant.

\begin{tabular}{lc|cc}
\hline \multicolumn{1}{c|}{ Population of Interest } & $n$ & $M$ & $S D$ \\
\hline Total children served in this age group (birth to 6) & 3651 & 28.08 & 28.16 \\
Autism & 761 & 5.89 & 9.89 \\
Autism + Nonverbal & 186 & 1.69 & 2.91 \\
Autism + Speech Sound Disorder (SSD) & 273 & 2.29 & 2.96 \\
Autism + Suspected Apraxia of Speech (sCAS) & 124 & 1.08 & 1.64 \\
Autism + Diagnosed Childhood Apraxia of Speech (CAS) & 55 & 0.48 & 0.93 \\
Autism + sCAS + Nonverbal & 64 & 0.58 & 0.99
\end{tabular}

Children with autism and CAS. On average, $21 \%$ of children currently served have a DSM-IV diagnosis of autism. On average, participants reported suspecting CAS in $16 \%$ of children with autism while an average of $7 \%$ of children with autism have a confirmed diagnosis of CAS. Table 4 shows the mean percentages of total children with autism who meet characteristics of the populations of interest in this study. 
Table 4

Mean percentage of children with autism who meet characteristics of the populations of interest

\begin{tabular}{lc}
\hline \multicolumn{1}{c}{ Population of Interest } & Mean Percentage \\
\hline Children with autism who are nonverbal & $24 \%$ \\
Children with autism who have a speech sound disorder & $36 \%$ \\
Children with autism who have suspected CAS & $16 \%$ \\
Children with autism who have a diagnosis of CAS & $7 \%$ \\
Children with autism and CAS (suspected or diagnosed) who & $52 \%$ \\
are nonverbal &
\end{tabular}

The mean number of children with autism who have suspected apraxia of speech on an SLP's caseload is related to the number of years as a certified SLP. A 2 tailed Spearman ranked correlation ( $\mathrm{rho}=0.9, \mathrm{df}=3$ ) was significant at the .01 level.

Participants who report being certified as an SLP for more years are suspecting that more children with autism have apraxia of speech.

The mean number of children with autism who have suspected apraxia of speech is related to the total number of children served with autism. A 2-tailed Spearman ranked correlation ( $\mathrm{rho}=0.67, \mathrm{df}=20$ ) was significant at the .05 level. SLPs who serve more total children with autism also serve more children with autism and suspected apraxia of speech.

Participants working in private practice and medical/hospital-based settings suspected CAS in at least one child with autism more often than participants who worked in other settings. Of the total number of participants working in private practice, $71 \%$ suspected CAS in at least one child with autism. Of the total number of participants 
working in medical or hospital-based settings, $65 \%$ suspected CAS in at least one child with autism. Less than $45 \%$ of participants in all other settings suspected CAS in at least one child with autism. There is also a difference in percent of SLPs who suspect CAS in at least one child with autism and work in urban vs. rural settings, with SLPs from urban settings more likely to suspect CAS in children with autism than their rural counterparts. See Table 5 for results.

Table 5

Percent of participants in each work setting who report suspecting CAS in at least one child with autism

\begin{tabular}{|c|c|c|c|}
\hline Work setting & Total & $n$ & $\%$ \\
\hline Private Practice & 35 & 25 & $71 \%$ \\
\hline Medical/Hospital-based & 17 & 11 & $65 \%$ \\
\hline University Clinic & 16 & 7 & $44 \%$ \\
\hline County/State Early Intervention & 30 & 13 & $43 \%$ \\
\hline Developmental Preschool & 22 & 8 & $36 \%$ \\
\hline Other ${ }^{\mathrm{a}}$ & 12 & 4 & $33 \%$ \\
\hline Public School & 24 & 6 & $25 \%$ \\
\hline Urban & 93 & 49 & $53 \%$ \\
\hline Rural & 28 & 10 & $36 \%$ \\
\hline
\end{tabular}

\section{Participants' Opinions on Autism}

Figure 3 displays the results from survey question \# 16: "According to the DSMIV, a child must exhibit qualitative impairments in social interaction and communication as well as restricted, repetitive, or stereotyped behaviors, interests, or activities. If you 
see a child with a core deficit in the area of pragmatics, do you feel that that is sufficient for a diagnosis of autism?" A high percentage of participants did not feel that a core deficit in the area of pragmatics is sufficient for a diagnosis of autism: $43 \%$ selected "strongly disagree" and 30\% selected "somewhat disagree."



$\square$ Strongly Agree

Somewhat Agree

๑ndecided

Somewhat Disagree

圆 Strongly Disagree

Figure 3. Participants' opinions on the assumption that a core deficit in pragmatics is sufficient for a diagnosis of autism.

Figure 4 displays the results from survey question \#17: “Children with autism who are nonverbal frequently have CAS." One third of participants who responded to this question were undecided while one fourth selected "somewhat disagree" and approximately one fifth selected "somewhat agree." 


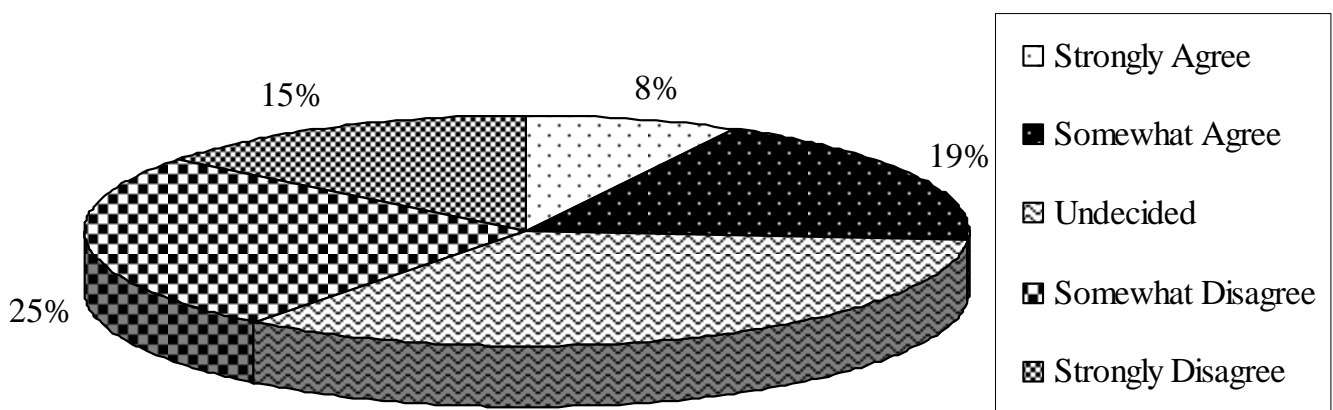

$33 \%$

Figure 4. Participants' opinions on the assumption that children with autism who are nonverbal frequently have CAS.

\section{Participants' Opinions on CAS}

Figure 5 displays the results from survey question \#18: "Effective treatment for

CAS should show immediate improvement." Responses to this question were mixed: $38 \%$ of participants who responded selected "somewhat disagree" while $26 \%$ selected "somewhat agree."

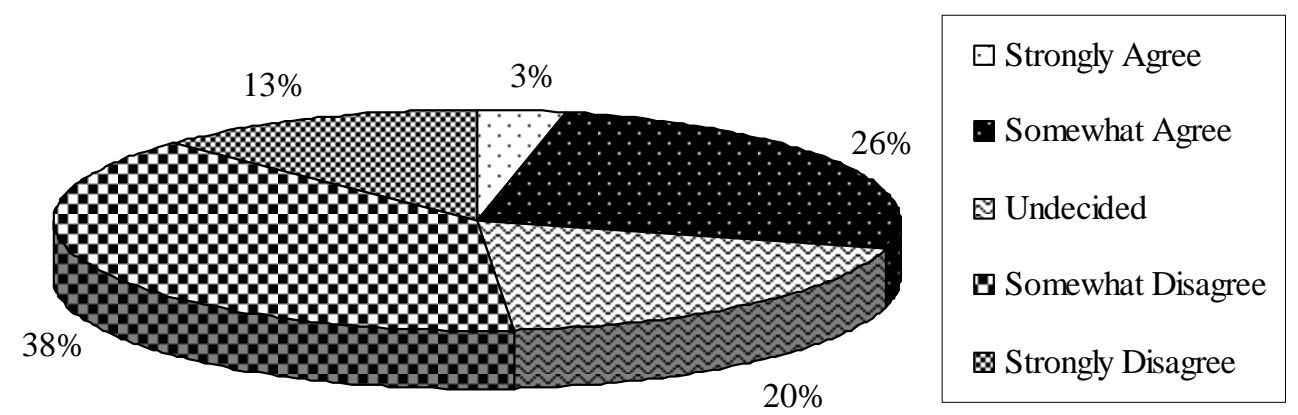

Figure 5. Participants' opinions on the assumption that effective treatment for CAS should show immediate improvement. 
Figure 6 displays results to survey question \#19: “According to ASHA's 2007 technical report on CAS, the following areas have been highlighted as specific areas of deficit: inconsistent error production on both consonants and vowels; lengthened and impaired co-articulatory transitions between sounds and syllables; and inappropriate prosody. Do you feel that all three of these areas must be impaired to make a diagnosis of CAS?" A high percentage of participants who responded to this question agreed with the assumption; more than half of the participants selected "somewhat agree" and $20 \%$ selected "strongly agree."

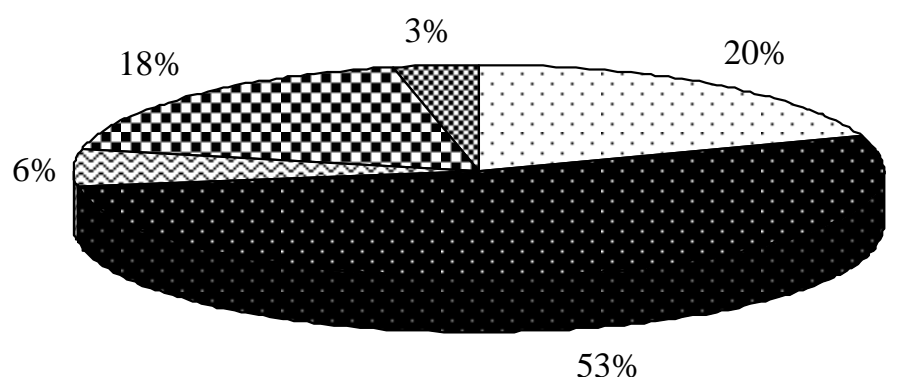

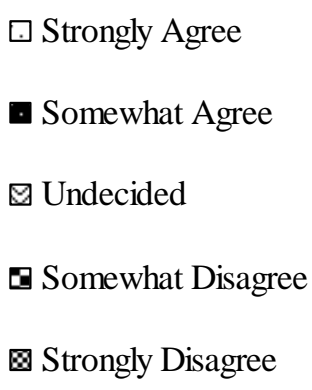

国 Strongly Disagree

Figure 6. Participants' opinions on the assumption that all three areas of deficit highlighted in ASHA's 2007 technical report on CAS must be impaired for a diagnosis of CAS.

\section{Assessment of CAS in a Child with Autism}

Of the total participants, $80 \%$ indicated that they would begin assessment for CAS in a child with autism as soon as they notice specific signs of CAS, while $24 \%$ indicated that they would assess for CAS if a child exhibits a certain number of signs of CAS. The number of signs thought to be necessary for suspected CAS ranged from 1 to 5 signs. Of these, $11 \%(n=12)$ indicated that they would begin assessment if a child exhibited only 1- 
2 signs of CAS while $9 \%(n=10)$ felt that 2 to 3 signs was necessary and $5 \%(n=5)$ waited to see 4 to 5 signs of CAS before beginning assessment.

Of the total participants, $20 \%$ indicated that they would assess for CAS if a child is not developing speech after a specified time of intervention. The specified amount of time ranged from $6-8$ weeks to $\geq 6$ months of intervention. Of these, $50 \%$ indicated that it would be concerning if the child is not developing speech after 6 months of intervention.

Of the total participants, $10 \%$ indicated that they would assess for CAS if a child is still nonverbal at a certain age. This age varied from 1 to 3 years with $45 \%$ of these participants indicating that the child would still have to be nonverbal at 3 years or older.

Nearly $10 \%$ of the total participants indicated that they have not assessed a child with autism for CAS either because they have not seen a child with autism and CAS, they do not do assessments, and/or they believe that children with autism are too difficult to assess for CAS. See Figure 7 for results. 


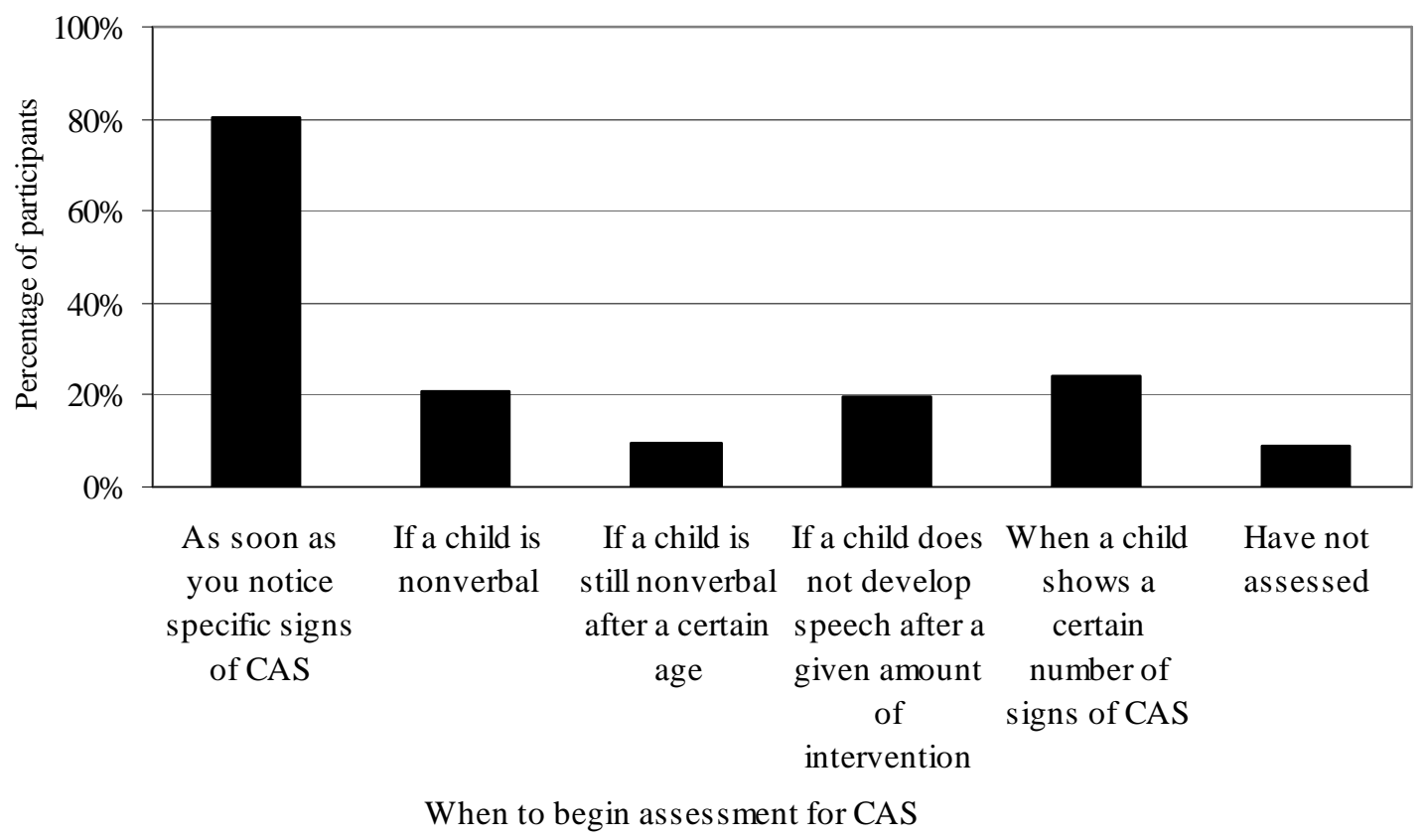

Figure 7. Participants' responses to survey question \#21 :" When do you begin assessment for CAS in a child with autism?"

\section{Specific speech characteristics used to make a diagnosis of CAS in a child}

with autism. Difficulty combining and sequencing phonemes and inconsistent production of speech sounds were the most commonly used characteristics used to diagnose CAS in children with autism. Difficulty combining and sequencing phonemes is used by $94 \%$ of the total participants as a key characteristic to use when diagnosing CAS. Inconsistent production of speech sounds is used as key characteristics to use when diagnosing CAS by $93 \%$ of the participants. More than $75 \%$ of participants also selected the following signs: groping with the speech mechanism (86\%); vowel deviations (80\%); and limited speech sound repertoire (77\%). A few participants (5\%) felt that weakness or paralysis of the speech mechanism was indicative of CAS. See Figure 8 for results. 




Speech characteristics

LSS = Limited speech sound repetoire
IPSS = Inconsistent production of speech sounds
VD = Vowel deviations
CS = Difficulty combining and sequencing phonemes
DIIC = Decreased intelligibility with increased
complexity
DIm = Difficulty with imitation
IP = Inappropriate prosody

Figure 8. Speech characteristics used to diagnose CAS in children with autism.

\section{Assessment Tools Used for Children with CAS and Autism. Participants}

reported a wide range of assessment tools used for children with CAS and autism (Figure 9). The most common tool was a connected speech sample (65\%) At least half of all participants reported using the following tools: oral mechanism exam (55\%); diadochokinetic tasks (52\%); imitation of multisyllabic words $(50 \%)$; trial period of intervention (50\%). Fewer participants reported using tests specifically designed to assess apraxia such as the Kaufman Speech Praxis Test (42\%), the Verbal Motor 
Production Assessment for Children (14\%), the Apraxia Profile (12\%), and the Screening

Test of Developmental Apraxia (4\%).

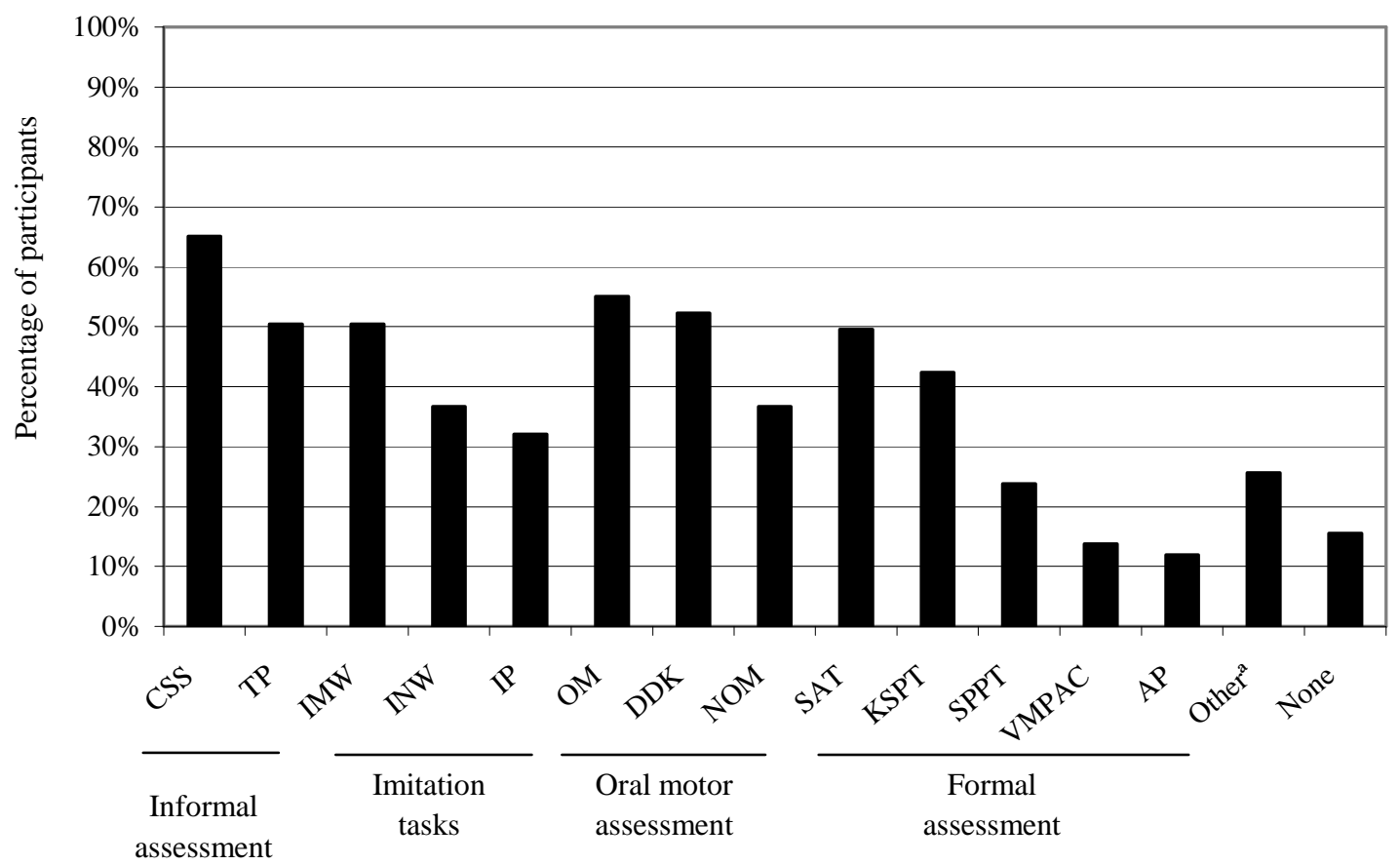

Assessment Tool

CSS = Connected Speech Sample

$\mathrm{TP}=$ Trial period of intervention

NOM = Nonspeech oral motor tasks

SAT $=$ Standardized articulation test

IMW = Imitation of multisyllabic words

KSPT $=$ Kaufman Speech Praxis Test

INW = Imitation of nonsense words

SPPT $=$ Standardized phonological processing test

IP = Imitation of phrases

VMPAC $=$ Verbal Motor Production Assessment for Children

$\mathrm{OM}=$ Oral mechanism exam

DDK $=$ Diadochokinetic tasks

$\mathrm{AP}=$ Apraxia Profile

Figure 9. Assessment tools used to diagnose CAS in children with autism.

${ }^{a}$ Screening Test of Developmental Apraxia, developmental history, informal observation, imitation of sounds or syllables, single word repetition, DEMSS (Dynamic Assessment of Motor Speech Skill), Early Motor Control Scales, PCC (percent consonants correct), syllable shape repetoire, prosodic findings, response to multisensory cueing, screenings from Childhood Apraxia of Speech (Velleman), imitation of vowels, "my own informal speech exam," phonetic inventory, PROMPT's evaluation. 


\section{Interventions for Children with CAS and Autism}

Figure 10 displays the results for interventions that have been used with children with CAS and autism. The most commonly used intervention technique that participants reported using for children with CAS and autism was augmentative and alternative communication (72\%). Fewer participants reported using integral stimulation (15\%) or melodic intonation therapy $(17 \%)$.

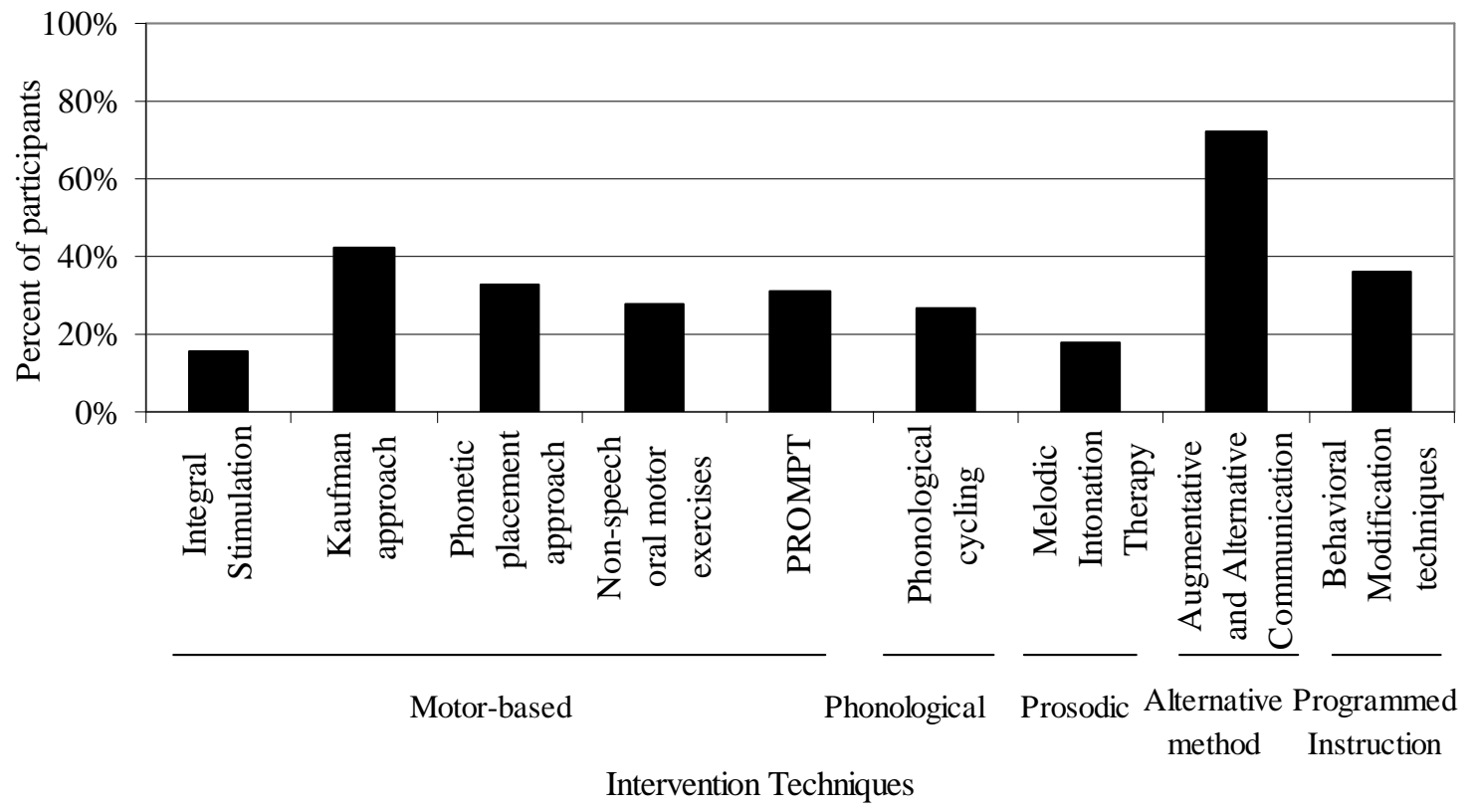

Figure 10. Interventions that have been used for children with autism and CAS.

Participants reported the most familiarity with PROMPT as an intervention technique used for children with CAS - 57\% reported that they were familiar with this technique. Participants reported the least familiarity with integral stimulation - only $19 \%$ reported familiarity with this intervention technique. Approximately half of all 
respondents to this question reported familiarity with the remaining interventions for CAS. See Figure 11 for results.

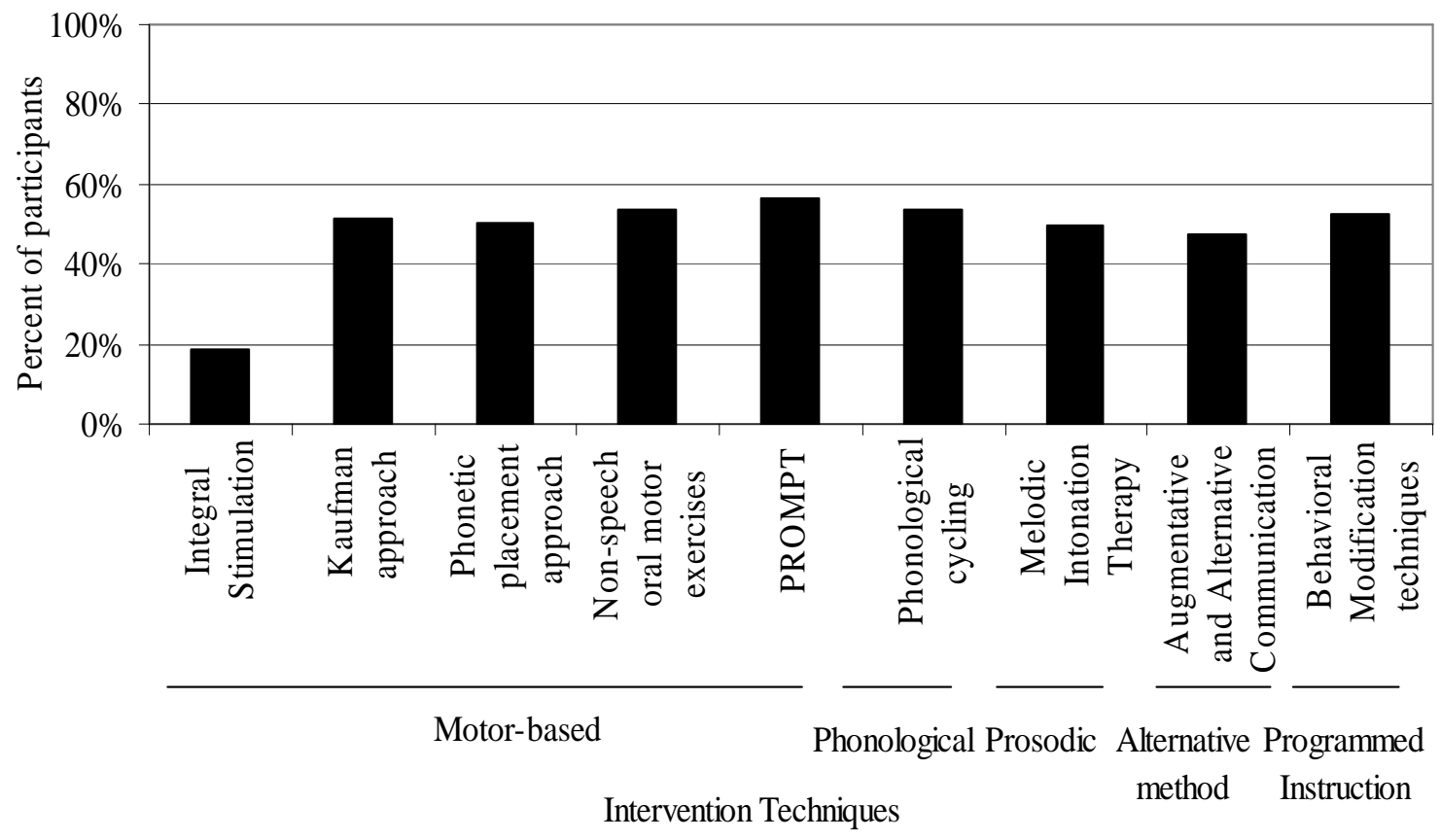

Figure 11. Familiarity of interventions for CAS.

Participants reported the most comfort with augmentative and alternative communication as an intervention for children with autism and CAS - 52\% indicated that they are comfortable with this intervention technique. Less than $40 \%$ of the total participants reported comfort with the motor-based approaches, which include integral stimulation, the Kaufman approach, phonetic placement approach, and oral motor exercises. Out of all the treatment techniques, participants were the least comfortable using integral stimulation and melodic intonation therapy to treat CAS - only $11 \%$ reported that they were comfortable using integral stimulation and $18 \%$ reported they 
were comfortable with melodic intonation therapy. Results on reported comfort with interventions for CAS are displayed in Figure 12.

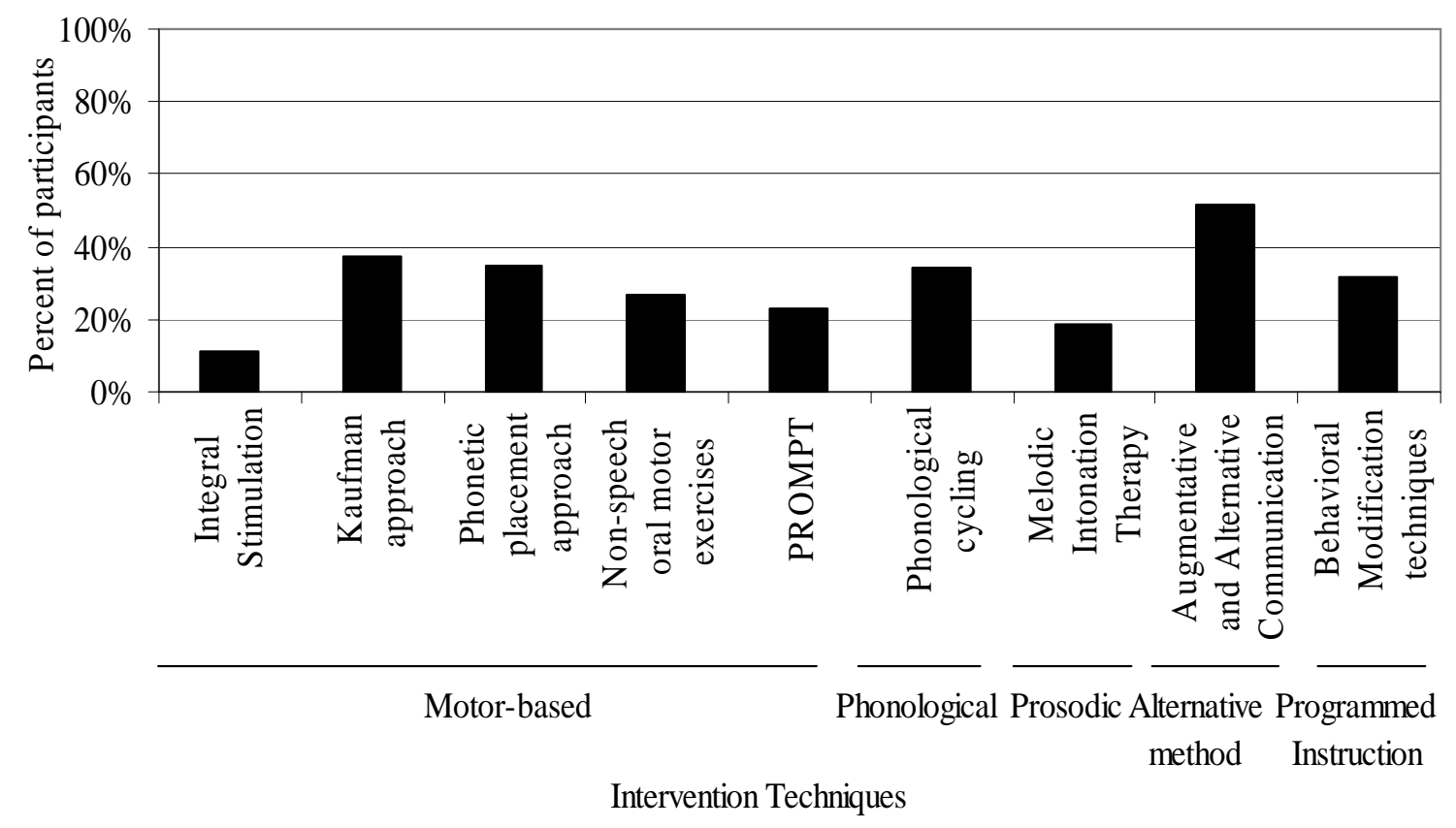

Figure 12. Reported comfort with interventions for CAS.

Figure 13 displays results for the perceived benefit of interventions for CAS that have been used for children with CAS and autism. At least $65 \%$ of those participants who have used the indicated intervention reported a perceived benefit with the use of each technique for children with CAS and autism. More than $80 \%$ of participants who have used integral stimulation, PROMPT, augmentative and alternative communication, behavioral modification techniques, and the Kaufman approach reported a perceived benefit for children with CAS and autism. 


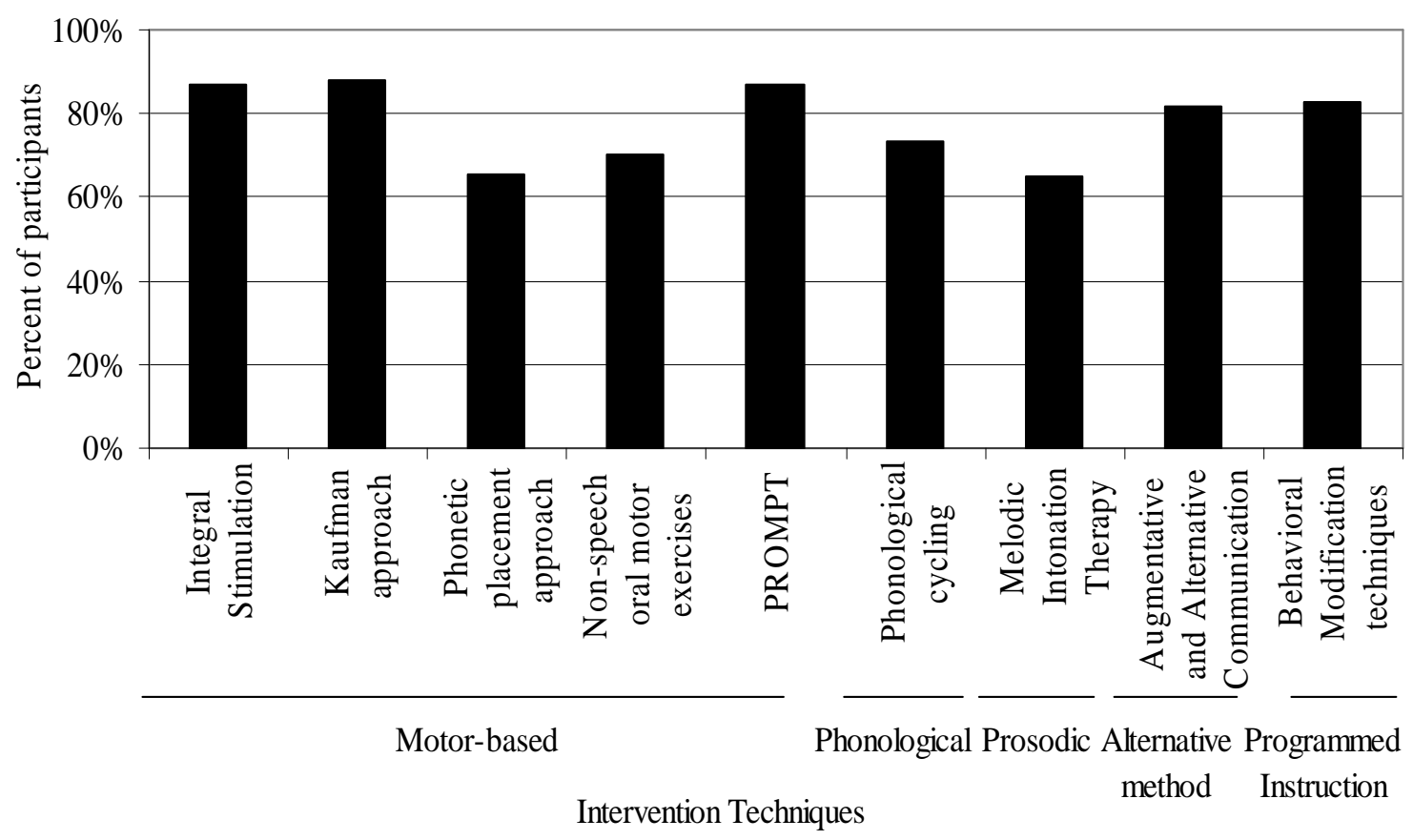

Figure 13. Perceived benefit of interventions for CAS when used for children with autism and CAS.

A high percentage of participants $(62 \%)$ indicated that they have no knowledge of integral stimulation as an intervention technique for CAS. The next closest technique that participants indicated no knowledge of was melodic intonation therapy; $22 \%$ reported no knowledge of this technique. Fewer than $20 \%$ of participants reported no knowledge of PROMPT and the Kaufman approach. Fewer than $10 \%$ of participants reported no knowledge of the other intervention techniques, including non-speech oral motor exercises, augmentative and alternative communication, behavioral modification techniques, phonological cycling, and the phonetic placement approach. Only $1 \%$ indicated no knowledge of augmentative and alternative communication as an intervention for CAS. See Figure 14 for results. 


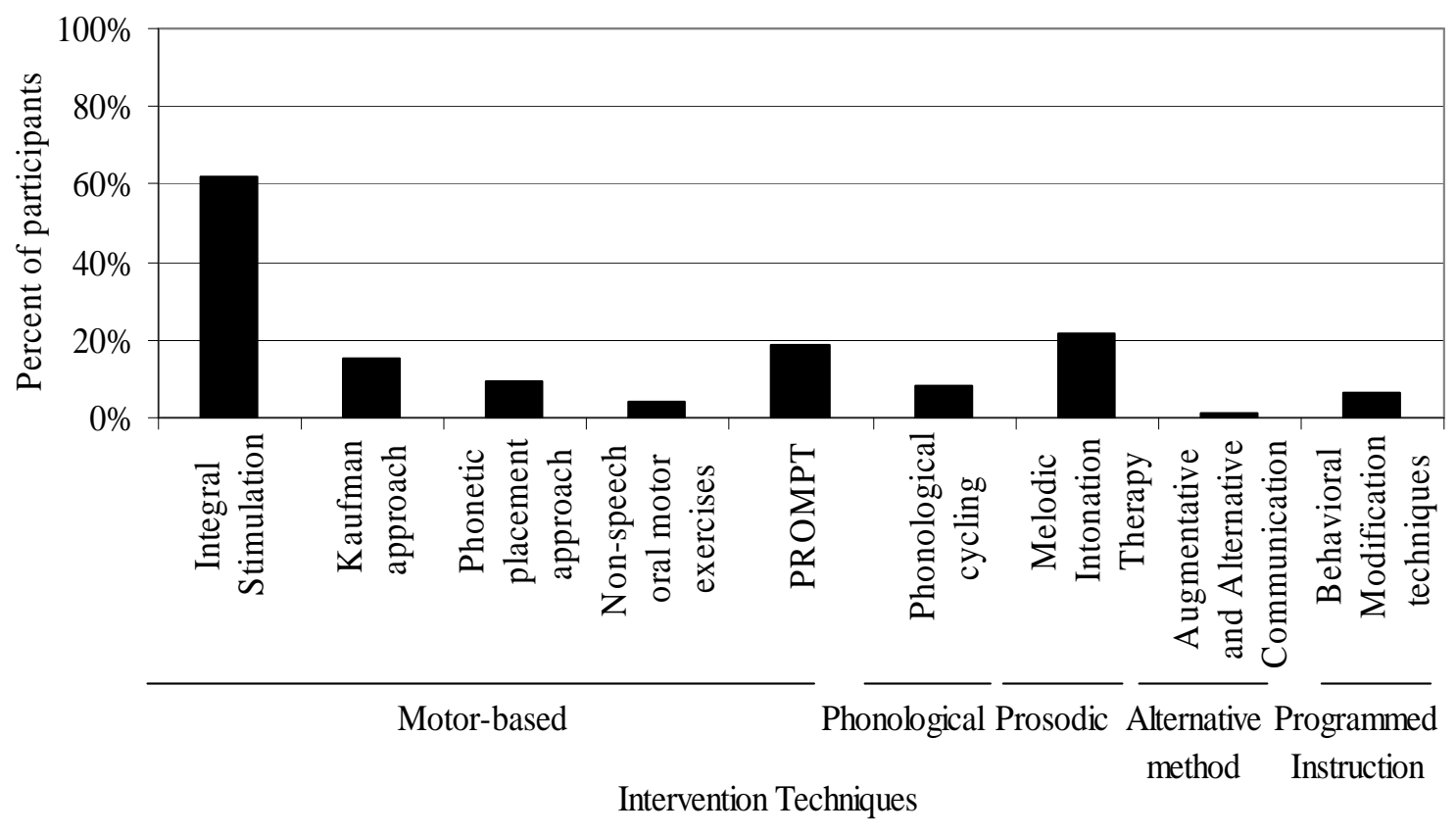

Figure 14. Interventions for CAS that participants report no knowledge of.

Treatment model. Results in Figure 15 reflect the treatment models used by participants. Of the total participants, $68 \%$ indicated that they implement treatment for CAS in a child with autism as part of a comprehensive treatment approach (i.e. treatment for CAS is incorporated into the overall treatment approach for children with autism). Only $6 \%$ of participants indicated that they target CAS in isolation from treatment for autism. Very few participants (3\%) indicated that they do not target the speech sound disorder. Similarly, only 3\% reported that they target CAS in isolation while other members of the treatment team implement more traditional treatment to target the impairments in social communication, social interaction, and repetitive behaviors or interests in children with autism. Several participants (21\%) indicated that either they do 
not provide treatment (i.e. they participate mainly in assessment) and/or they have not provided treatment for this population.

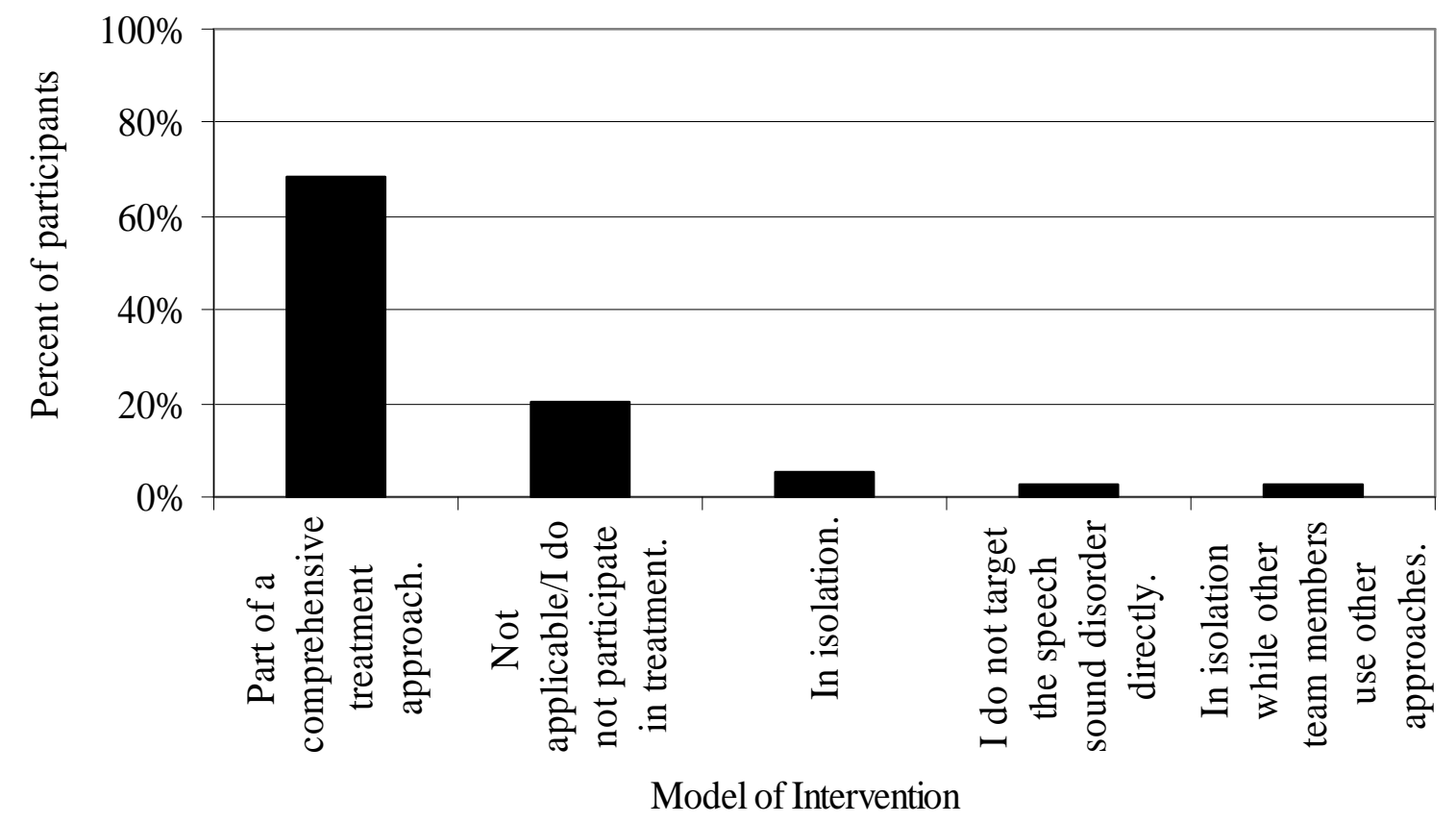

Figure 15. Models used by SLPs to implement treatment for CAS in children with autism.

Treatment method decisions. A high proportion of participants, $82 \%$, indicated that they rely on their personal clinical judgment when selecting the treatment method to use for children with autism and CAS. Research-based information was also commonly used to select a treatment method $-73 \%$ indicated that they rely on research-based information. Other common methods of selecting a treatment approach included using information learned in continuing education courses (63\%), collaborating with the family $(58 \%)$, and referring to assessment results $(56 \%)$. See Figure 16 for results. 


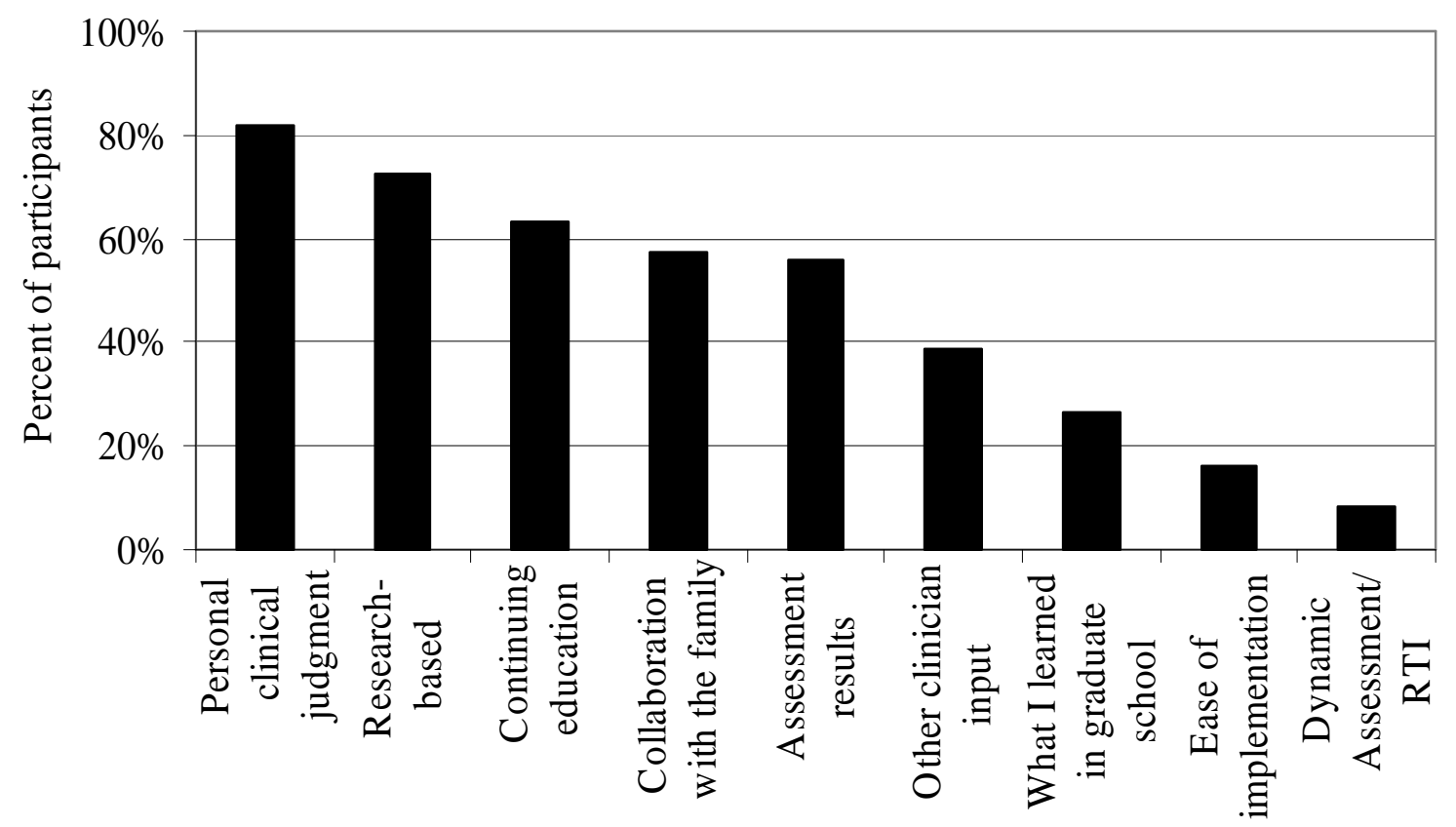

Selection Method

Figure 16. How treatment methods for CAS in children with autism are selected.

Overall, results suggested that SLPs are currently using a wide variety of both assessment tools and intervention techniques for children with autism and suspected CAS. Implications of these results will be discussed in the next section. 


\section{Discussion}

In the current study, speech-language pathologists working throughout the United States with children ages 0 to 6 years were asked to respond to a Web-based survey regarding their experience with children with autism and suspected childhood apraxia of speech. The purpose of the study was to determine if SLPs are suspecting CAS in some children with autism and to identify the assessment and treatment methods implemented for children with autism and suspected CAS.

There is currently a paucity of research examining characteristics of CAS occurring in children with other developmental disorders. The possibility of CAS occurring in children with Down syndrome has recently been introduced (Kumin, 2006). Teverosky, Bickel and Feldman have also suggested that it may be possible for some children with CAS to have a developmental condition such as autism (2009). The current study has begun to examine the possibility that some children with autism, particularly those who are nonverbal, may have CAS. Due to the limited data on this population to date, the results of the survey will help to identify areas for future research, particularly a need for the development of guidelines for assessment and treatment of CAS in children with autism.

First, this discussion will address whether the SLPs who responded to the survey are suspecting CAS in children with autism. The possibility that certain sub-populations of SLPs (e.g. SLPs working in the field for 20+ years) are suspecting CAS in children with autism more often than others will also be addressed. Possible explanations for why 
certain SLPs are suspecting CAS in children more often than others will be suggested and explored.

Responses have been analyzed to determine if many of the children with CAS and autism are nonverbal. Implications from these results will be discussed. Also, the challenges associated with diagnosing CAS in a nonverbal child with autism will be explored.

The discussion will also examine the assessment tools that are currently being used when CAS is suspected in a child with autism. Along with this, the discussion will identify the characteristics of CAS that most commonly lead SLPs to suspect CAS in a child with autism. The consequence of relying on a wide variety of characteristics to identify CAS in children with autism will be presented.

Finally, treatment methods that have been implemented for children with autism and CAS and implications regarding the mixed results of participants' knowledge and use of varied treatment methods for CAS will be discussed. Lastly, suggestions regarding treatment for CAS as part of a comprehensive treatment approach for children with autism will be presented.

\section{Potential Bias of Survey Participants}

First, it is important to examine the characteristics of the SLPs who participated in this survey. It should be noted that the primary sampling method used in this study, snowball sampling, has likely resulted in a non-randomized and biased sample of participants. Snowball sampling was used because there was not another practical and reliable method to select a truly randomized sample of all SLPs in the United States 
together with the fact that the target population was so small- so few SLPs would be working with children ages 0-6 years. The "snowball" originated with professors from Portland State University, all of whom possess doctoral degrees. These professors were asked to distribute the survey to their colleagues across the United States. The result was that a high amount $-13 \%$ of the sample, had Ph.D.s. Therefore, the participants in this study may reflect a higher level of education than the entire population of SLPs in the United States.

Also especially important to recognize is the fact that Dr. Christina GildersleeveNeumann, the committee chair to this thesis, was a member of the American Speech and Hearing Association's Ad Hoc Committee on Apraxia of Speech in Children. Many of Dr. Gildersleeve-Neumann's colleagues who received a request to complete the survey were also experts on childhood apraxia of speech. Therefore, a significant portion of survey participants may have specialized knowledge and training on the topic of CAS. Along with this, some participants may serve or evaluate a disproportional number of children with CAS. As a result, participant responses may not truly reflect the experiences and knowledge of all SLPs in the United States. Despite the biases explained here, however, the results of this survey should still be considered important and can make a meaningful contribution to this relatively new area of research on CAS in children with other developmental disorders.

\section{Are SLPs Currently Suspecting CAS in Children with Autism?}

Results of the survey revealed that SLPs are suspecting CAS in some children with autism. On average, approximately 1 out of 5 children with autism served per 
participant was reported to have suspected CAS. It is important to recognize that this is an average, and there were many SLPs who have not seen children with autism and CAS and others who have seen more than 1 in 5 children with autism with characteristics of CAS. Overall, however, these results are a clear indication that some children with autism are indeed reported to have characteristics of CAS. These initial results support data from Teverovsky, Bickel and Feldman's study (2009) which found that over half of the children with CAS involved their study had co-occurring health, mental health, and developmental conditions, including autism.

Participants indicated that approximately half of the children with autism and suspected CAS are nonverbal. It was hypothesized that many of the children with autism and CAS would be considered nonverbal. In this way, CAS may be contributing to the fact that the child is nonverbal - not only may the child seem unmotivated or uninterested in using speech to communicate socially, but they may also lack the motor planning abilities to physically produce speech sounds and then sequence them together to form intelligible speech. However, it is truly challenging, if not impossible, to determine if a nonverbal child is affected by CAS. A traditional diagnosis of CAS requires a child to produce enough speech (at least 50 words) in order for the SLP to recognize the signs that are suggestive of CAS. Therefore, it may be that more nonverbal children with autism have CAS than was reported by participants, but that it is impossible to determine such a diagnosis using current diagnostic guidelines when the child is not producing enough speech to conduct a full assessment for CAS. 
Significantly fewer children with autism and suspected CAS (approximately 1 in 12 children with autism) have actually been diagnosed with CAS. Among other factors, some of the challenges discussed above in regard to nonverbal children may contribute to the fact that many more children with autism have suspected CAS in comparison to diagnosed CAS. Other reasons for the great difference between numbers of children with autism and suspected CAS and diagnosed CAS may be: SLPs' lack of knowledge regarding the possibility of CAS occurring in children with autism, preference not to add a second diagnosis to a child with a primary diagnosis of autism, or SLPs' lack of knowledge of either autism or CAS.

As has been mentioned several times, there is a paucity of research on the topic of CAS occurring in children with autism as well as how it should be diagnosed. SLPs may be reluctant to make a diagnosis of CAS in children with autism when there has not yet been research to confirm that CAS does indeed occur in children with autism. Also, if a child already has a primary diagnosis of autism, in most settings the child is eligible to receive any speech and language services that are necessary. Therefore, if an SLP suspects CAS, they may add in treatment for the speech sound disorder to their overall treatment approach for the child without adding a second diagnosis of CAS.

Results of the survey suggest that all SLPs may not have the same understanding of autism and CAS, respectively. Although $43 \%$ of participants strongly agreed that a deficit in pragmatics is not sufficient for a diagnosis of autism, 20\% indicated that they either strongly or somewhat disagreed; this $20 \%$ felt that a core deficit in pragmatics is sufficient for a diagnosis of autism. According to the DSM-IV, autism is classified by a 
qualitative impairment in social communication and social interaction together with stereotyped or repetitive behaviors or interests. The DSM-IV definition of autism clearly encompasses more than just a deficit in the use of language (i.e. pragmatics). Also, 7\% of participants were undecided regarding a core pragmatic deficit in children with autism. Overall, $27 \%$ of participants expressed a misunderstanding regarding the requirements for a diagnosis of autism. These results suggest that not all SLPs have the same or correct information regarding the diagnosis of autism.

Responses to question number \#17 (“Children with autism who are nonverbal frequently have CAS”) suggest that SLPs have conflicting opinions regarding nonverbal children with autism. Results were almost split evenly - one third of participants selected "undecided," while a little less than one third responded with either "somewhat" or "strongly agree" and a little more than one third of participants selected "somewhat" or “strongly disagree." Such mixed results suggest that many SLPs are unsure if a child with autism who is nonverbal most often has CAS. Most likely, not all children with autism who are nonverbal have CAS. In this study, it was hypothesized that many of the children with autism and CAS would be nonverbal but not necessarily that all of the children who are nonverbal would have CAS. Many other factors related to autism could be contributing to the fact that a child with autism is nonverbal; it should not be assumed that all nonverbal children with autism have CAS. Some participants may be assuming the opposite, which could result in a misdiagnosis of CAS.

Similar results were found regarding the participants' knowledge of CAS. Nearly $75 \%$ of the total participants indicated that they either somewhat or strongly agreed that 
the three areas of deficit highlighted in ASHA's 2007 technical report (i.e. inconsistent error production on both consonants and vowels; lengthened and impaired co-articulatory transitions between sounds and syllables; and inappropriate prosody) on CAS must be impaired for a diagnosis of CAS. Contrary to this statement, there is not currently a validated list of diagnostic features of CAS to distinguish it from other types of childhood speech sound disorders and the three stated areas are not necessary or sufficient signs of CAS (ASHA, 2007b). The three areas highlighted in the technical report are areas that seem to have some consensus among researchers, but it has not been determined that all must be present for a diagnosis of CAS. A large majority of the participants indicated that they believe there must be impairments in all three of the areas for a diagnosis of CAS. Perhaps many SLPs are only seeing one or two of those three main characteristics and therefore suspect that a child has CAS but do not believe they can make a true diagnosis without all three areas of deficit present.

Another concerning result of the survey is that $5 \%$ of participants indicated using weakness or paralysis of the speech mechanism as a diagnostic characteristic of CAS in children with autism. Weakness or paralysis is typically indicative of dysarthria and not apraxia. If SLPs are using this as diagnostic marker, they may be misdiagnosing some children with CAS. Lastly, the finding that nearly half of the children reported to have CAS and autism are nonverbal suggests that participants did not all have an accurate understanding of CAS. Considering the current diagnostic criteria for CAS, it is impossible to diagnose CAS in a child who is nonverbal, whether the child is also affected by autism or not. Participants' responses indicate that they are making 
inaccurate diagnoses by identifying CAS in a child who is nonverbal. Though it may be appropriate to suspect the interference of CAS on a child's ability to use speech, identification of CAS is not possible until the child is using an adequate amount of speech to recognize the characteristics of CAS. Responses to the questions regarding diagnostic markers for both autism and CAS suggest that all SLPs do not have a shared understanding of these disorders; some SLPs may be misinformed on autism and/or CAS and therefore may be misdiagnosing children who actually have one, both, or neither of the disorders.

One of the questions intended to measure participants' knowledge about CAS did not provide clear results. Question \# 18 asked for participants' opinions on whether effective treatment for CAS should show immediate improvement. Mixed results suggested that the question was worded improperly. One of the common signs of CAS is often that the child is making slow progress in traditional articulation treatment (i.e. no progress is observed after 3-4 months of intervention). The concept of "slow progress" may also be misunderstood by some SLPs - some may think that progress will not be seen for a year or more. Early intervention is such a key to success for children with CAS that waiting an entire year for progress puts the child at a disadvantage. That means the child has lost an entire year during which more appropriate treatment could have been implemented to effect change. Once treatment for CAS is introduced, the child's speech should begin to improve. "Immediate" may have been a misleading term to use in reference to the child's improvement, however. Some participants may have interpreted "immediate" as it was used in this question to compare to the slow progress in other 
treatment. "Immediate" could have been interpreted as improvement within the first few weeks, months, or even within the first year. Therefore, some SLPs may be expecting to see improvement in the short-term while others might see a need for a year or more of treatment in order to see improvement. Treatment for CAS should show improvement in the short-term (i.e. within 3-6 months), however all not SLPs may have interpreted this to mean "immediate."

Another possible contributing factor to the interpretation of this question is the type of intervention being used. For example, if participants were using AAC, improvement may come about more quickly than if they were using a focused motorbased approach such as Integral Stimulation. Due to the possibility of different interpretations of this question, the results will not be used to reflect whether participants have the correct expectation regarding the effectiveness of treatment for CAS.

\section{Relationships between participant-related factors and number of children}

with autism and suspected CAS. Results revealed that the number of years as a certified SLP as well as the total number of children with autism served are related to the number of children reported to have autism and suspected apraxia of speech. SLPs who have worked in the field the longest appear to be suspecting apraxia in children with autism more often than those have been in the field for a shorter amount of time.

Although these SLPs probably did not learn about CAS or autism during their graduate program, they may have had more chances to attend continuing education courses. Although apraxia of speech is not new to the field of speech pathology, childhood apraxia of speech is relatively new to the field. Autism is similarly new to the field of speech 
pathology. Accordingly, there are likely to be many continuing education courses on the topics of CAS and autism. SLPs who have been in the field longer may have had a chance to learn more about CAS and autism than SLPs who have not been in the field as long. This is also an important area to remember the possible bias of participants in this study. It may be possible that many of the SLPs in this study who have been in the field for a longer amount of time may also have a special interest in CAS; many are colleagues of Dr. Gildersleeve-Neumann. So, the results regarding a relationship between number of years as a certified SLP and number of children with autism and suspected apraxia of should be taken with caution - they should not be applied to the entire population of SLPs in the United States. With the results of this survey, there is no way to know if the participants did indeed have extra knowledge or interest in CAS. If this survey was replicated it would be useful to ask for specifics on if participants felt they had specialized knowledge of the topics (i.e. autism or CAS) as well as where they gained that knowledge.

The further relationship found in the results is that SLPs who serve more total children with autism have also identified more children with autism and suspected apraxia of speech. This result is important as it demonstrates that an even proportion of children with autism and suspected CAS are being identified across SLPs. If this relationship did not exist, it would be necessary to question why some SLPs who see more children with autism are not identifying as many children with autism and suspected apraxia of speech as those who see fewer total children with autism. The positive relationship is encouraging and suggests that the approximate average of 1 in 5 
children with autism reported to have suspected apraxia of speech may be applicable across SLPs.

Lastly, participants working in private practice and medical or hospital-based settings reported an increased number of children with autism and CAS. This could be a result of interdisciplinary practice - perhaps the presence and contribution of other professionals with specific knowledge of autism and/or CAS leads to an increased rate of diagnosis? However, this finding could also be a result of coding and/or billing practices. Perhaps a secondary diagnosis results in increased benefits and/or payments from an insurance company. It is interesting that the significance of a secondary diagnosis can vary so much across settings.

\section{Assessment of Suspected CAS in a Child with Autism}

Survey results revealed that criteria for when to begin assessment for CAS in a child with autism varied widely across participants. The most common indicator for when to begin assessment was as soon as specific signs of CAS are noticed $-80 \%$ of participants selected this answer. Specific speech characteristics are often used for a diagnosis of CAS in otherwise typically developing children, however even then it can be difficult to make a determination of CAS because many of the diagnostic markers of CAS also occur in children with other speech sound disorders (Davis and Velleman, 2000).

The presence of other developmental disorders, such as autism, can confound the difficulty of making a diagnosis of CAS. The difficulty of determining diagnostic speech characteristics may be leading some SLPs to look to other diagnostic markers when beginning an assessment of CAS in a child with autism. Results indicated that some 
SLPs $(24 \%)$ look for a certain number of signs (ranging from 1 to 5), others (20\%) begin to consider CAS if a child is not developing speech after a specified time of intervention (ranging from 6 weeks to 6 months) while others (10\%) prefer to wait and assess for CAS if a child is still nonverbal by a certain age (ranging from 1 to 3 years). To date, no research studies have specified requirements in any of these areas for a diagnosis of CAS; a certain number of signs necessary for a diagnosis of CAS has not been determined, just as it has not been determined that a child should be assessed for CAS if they are still nonverbal after a specified time of intervention or by a certain age. Currently, the most commonly used and research-based indicator for when to begin assessment is as soon as specific speech characteristics of CAS are noticed.

The most common signs that participants watched for included: difficulty combining and sequencing phonemes, inconsistent production of speech sounds, groping with the speech mechanism, vowel deviations, and limited speech sound repertoire. Davis and Velleman (2000) listed similar inclusionary speech characteristics, but included suprasegmental abnormalities as one of the most common features. Only half (54\%) of the total participants included inappropriate prosody as a key speech characteristic for CAS in a child with autism. Inappropriate prosody or suprasegmental abnormalities may be a difficult diagnostic marker for CAS in children with autism; children with autism often exhibit atypical prosodic production (Schoen, Paul, \& Chawarska, 2009; Shriberg et al., 2001). However, inappropriate prosody can manifest differently in the two populations. Toddlers with autism may exhibit a sing-song pattern in their speech production (Schoen, Paul, \& Chawarska, 2009). However, older children 
with autism can speak in a monotone manner (Shriber et al., 2001). In contrast, children with CAS may use excess and equal stress when speaking - certainly a suprasegmental abnormality, however a different type of abnormality than is often seen in children with autism. Considering these differences, suprasegmental abnormalities as a whole may not be an appropriate diagnostic marker of CAS in children with autism. Inappropriate prosody and/or suprasegmental abnormalities should be operationally defined in children with autism vs. children with CAS. And so, excess equal stress (a prosodic maker of CAS) in a child with autism would warrant further investigation into the possibility of CAS. However, if a child is exhibiting a prosodic impairment consistent with autism, the impairment should not be regarded as a diagnostic marker of CAS. The results suggest that some of the diagnostic markers of CAS in children who are otherwise typically developing may need to be more clearly defined when considering the presence CAS in a child with autism. Future research is needed in order to determine if some of the typical diagnostic markers of CAS may need to be further defined in a child with autism and CAS.

Altogether, 22 characteristics were cited by participants as key diagnostic markers. Although this is fewer than Forrest's (2003) 50 characteristics identified as "necessary" for a diagnosis of CAS by 75 SLPs, 22 possible characteristics still highlight inconsistent and possibly contradictory criteria. Forrest (2003) suggested that further research is needed in order to further define the key clinical criteria for a diagnosis of CAS. Results from the current study suggest that it may be beneficial to define clinical criteria specifically for a diagnosis of CAS in children with autism as well. 
Assessment tools used for children with CAS and autism. Results of the survey indicated that up to 29 different assessment tools are being used by SLPs to assess CAS in children with autism. At least $50 \%$ of the total participants indicated using at least 1 of the 5 following assessment tools: connected speech sample, trial period of intervention, imitation of multisyllabic words, an oral mechanism exam, and diadochokinetic tasks. The most commonly used tool, a connected speech sample, was endorsed by $65 \%$ of participants as a valuable tool in the assessment of CAS. A connected speech sample allows the clinician to look for some of the key speech characteristics common to CAS. The second most commonly used tool, an oral mechanism exam, was selected by $55 \%$ of participants. This exam is valuable in order to assess non-speech oral-motor abilities as well as to determine if there are any physical abnormalities present and also allows the clinician to determine if there is any weakness apparent in the oral mechanism. However, an oral-mechanism exam may be more difficult to implement with a child with autism, given the possibility of a deficit in imitation and/or challenges related to cognition such as understanding and following directions.

Imitation of multisyllabic words and diadochokinetic tasks are also common tasks in the assessment of apraxia both in children and adults. A trial period of intervention (e.g. Response to Intervention) can be valuable if CAS is suspected but cannot be diagnosed - if treatment for CAS appears effective, the SLP may suspect CAS and continue to treat the disorder as such. The use of up to 24 additional assessment tools suggests that a clearly defined assessment battery for CAS has not been determined. 
Additionally, several participants noted that they suspect it would be very difficult for a child with autism to participate in many of the traditional tasks required in an assessment of CAS.

Results of this survey suggest that SLPs prefer to rely on more informal assessment measures when working with children with autism. The assumption that the formal assessment tasks may be difficult for children with autism may be underlying the finding that fewer participants reported using tests specifically designed to assess apraxia. These tests include: the Kaufman Speech Praxis Test, the Verbal Motor Production Assessment for Children, the Apraxia profile, and the Screening Test of Developmental Apraxia. Formal, standardized assessments can often be difficult to complete when working with children with autism, particularly children who are nonverbal, however it is not impossible. It is common practice to use standardized, norm-referenced measures to diagnose a child with autism, which demonstrates that at times it is possible, and indeed necessary to use standardized measures with this population.

Further points to consider when selecting standardized measures for assessment of apraxia are the reliability and validity of the measures. In a review of standardized tests of motor speech disorders, McCauley and Strand (2008) concluded that basic psychometric standards were deficient in all six of the tests reviewed (the study included the tests mentioned above as well as two other tests for nonverbal oral and speech motor performance). Given this information, the use of informal measures may be an appropriate alternative for the assessment of apraxia at this time - both for children with autism and CAS and children who are otherwise typically developing. McCauley and 
Strand caution if standardized measures are part of a clinician's clinical decision making process in children's motor speech disorders, the findings should be interpreted cautiously and with the psychometric properties in mind.

Given the frequent challenges of using standardized measures with this population together with the inefficient psychometric properties, it is impossible to identify or define one assessment battery that would be the most effective when suspecting CAS in this population, or any population. However, when such a wide variety of assessment tools are being used, it would be expected that a variety of results will therefore be revealed. Some of the diagnostic inaccuracies of CAS in children with autism demonstrated by the results of this study may be a result of the use of such a wide variety of assessment tools. Further research to determine the most accurate and behaviorally-appropriate assessment tools for children with autism and CAS are essential for the accurate diagnosis of this disorder.

\section{Treatment Methods for Children with Suspected CAS and Autism}

AAC for children with CAS and autism. Results revealed that while a variety of treatment approaches have been used for children with CAS and autism, there are specific approaches that SLPs appear more comfortable with than others. Participants' responses revealed that augmentative and alternative communication (AAC) is used most often for children in this population while participants report the least knowledge of and experience with integral stimulation treatment.

There has been a limited amount of research on AAC as an effective treatment for children below the age of 6 with CAS. Cumley and Swanson (1999) reported improved 
communication for 3 children with severe CAS with the use of AAC, however only one of those children was younger than 6 years old. This child was 3 years old and was impacted with severe CAS. Interventions initially involved touch cues associated with hand signals as well as melodic intonation therapy (MIT) to target syllable shape production. This treatment showed minimal improvement over 12 weeks. It was only after these interventions were unsuccessful that AAC was introduced to increase expressive language skills. It is also important to note that the AAC approach was multimodal, incorporating natural speech and gestures to facilitate language. In the current study, it is unclear from the participants' responses if their experience with AAC and children with CAS incorporated a multimodal approach. The case study presented by Cumley and Swanson suggests that AAC may be effective for a child with severe CAS who is unsuccessful in traditional articulation therapies and when it is implemented using multiple communication modalities.

Research on AAC for children with autism has shown that it can be effective in increasing communication and decreasing negative behaviors. Oftentimes, AAC systems for children with autism are low-tech, utilizing picture exchange systems which are most commonly used to target functional communication attempts such as requesting or rejecting objects or actions. Light, Roberts, Dimarco, and Greiner (1998) reported the effectiveness of AAC in a case study of a 6-year old boy with autism and severe expressive and receptive language deficits. Both high- and low-tech systems were implemented. The other critical part of the intervention for this child was the availability of support from facilitators to (1) operate, maintain and continue developing the AAC 
systems, and (2) use appropriate interaction strategies. The child made significant gains in both receptive and expressive communication and his natural speech also improved significantly.

Some of the survey questions regarding treatment methods may not have provided specific enough information, particularly concerning the use of AAC. Given the multitude of high and low tech options available when using AAC, it would have been beneficial to qualify the survey questions to specify high- or low-tech AAC devices. It is likely that one type of AAC that several participants have used was the Picture Exchange System (PECS; Bondy \& Frost, 1994). Bondy and Frost have demonstrated the effectiveness of PECS for children with autism, and although an increase in speech production has been seen in some children during the later phases of PECS intervention (Preston \& Carter, 2009), the system was not designed to target speech production. PECS targets initiation in a social context and focuses on intentional and functional communication attempts. PECS was not designed to treat a deficit in speech production. In this way, if some participants have used PECS for children with autism and CAS as an approach to target speech production, they have been implementing the approach incorrectly. Further research into the specific types of AAC used by SLPs for children with autism and CAS will provide a clearer picture of whether or not SLPs are implementing the approaches correctly and which approaches are yielding an increase in spoken language production.

It may also have been beneficial to ask the participants how AAC is incorporated into their treatment (e.g. if spoken language is encouraged together with the use of AAC) 
as well as if participants specify separate goals for communication vs. speech production while using AAC. Evidence for the use of AAC with both children with CAS and children autism suggests that AAC should be implemented in a multi-modal approach, encouraging natural speech and gestures for communication in addition to the use of the AAC device.

There is yet to be research done in the area of AAC for children with CAS and autism. Considering the research supporting AAC for children with CAS and children with autism separately, it seems that using AAC may be an effective approach for some children with autism and CAS. Important considerations when selecting AAC as a possible treatment method for a child with autism and CAS include the age of the child, the severity level of the CAS and autism, motor skill abilities, the overall treatment model being used and the available support from facilitators. Due to the motor demands involved in the use of both high- and low-tech AAC devices, an assessment of motor skills, cognition, and limb praxis should always be conducted when considering AAC as a treatment option. Considering the known motor skill impairments in children with CAS as well as some children with autism, a thorough assessment of motor skills should be completed before AAC is introduced as a treatment option for children with CAS and autism.

Other treatment approaches for children with CAS and autism. Other common treatment methods reported by participants included the Kaufman approach and PROMPT. The Kaufman approach was the second most commonly used intervention $42 \%$ of participants reported that they have used this approach. Although a commonly 
used approach for the treatment of CAS, there are currently no published research articles that report on the use of the Kaufman approach. The Kaufman method begins with word approximations and refines and reinforces the attempts toward whole target words and phrases. Kaufman and Kasper wrote an online article for apraxia-kids.org suggesting the use of the Kaufman method for children with autism who also exhibit apraxia of speech. Kasper and Kaufman refer to unpublished data, pre and post videotapes and anecdotal data to support the use of the Kaufman method with children with autism. Although the evidence to date is promising, published scientific research for this approach would increase its efficacy.

Participants report the most familiarity (57\%) with PROMPT as a treatment for CAS. However only about half of those participants indicated that they have used the approach. PROMPT requires a separate certification and it is possible that although participants are familiar with the approach, they are may not be certified to use it. It would have been useful to ask the participants to specify whether or not they are PROMPT certified to discover whether or not this influenced their responses to these questions. PROMPT (Hayden, Wetherby, \& Prizant, 1999) is a motokinesthetic approach which uses tactile cues and prompts to guide the articulators for speech production. Chumpelik (Hayden) first published the approach for the treatment of apraxia in 1984. It is likely that participants report the most familiarity with this approach due to the long-standing evidence for its effectiveness (Chumpelik (Hayden), 1984; Hayden, Wetherby, \& Prizant, 1999; Rogers et al., 2006). To date, there have not been any studies published on the use of PROMPT for children with autism and CAS. 
However, as it is a multisensory approach (utilizing touch, pressure, kinesthetic, and proprioceptive cues) and does not rely on imitation alone, it may be a very effective approach for children with autism and CAS who have difficulties with imitation.

Surprisingly, very few participants reported knowledge of integral stimulation treatment for CAS. Only $15 \%$ of the participants reported that they have used integral stimulation, $19 \%$ report they are familiar with the treatment and only $11 \%$ report that they are comfortable using the treatment. Although first introduced as a treatment for adults with apraxia of speech, it was modified for children with CAS by Strand and Debertine in 2000. Considering this, it is a relatively new approach for the treatment of CAS, which may be why such a high percentage (62\%) of the participants have no knowledge of the method. Despite the fact that integral stimulation is a relatively new treatment for CAS, there is mounting evidence to support its use for children with CAS. The survey results also suggest effectiveness of the treatment $-87 \%$ of participants who have used integral stimulation report a perceived benefit for children with CAS and autism (it should be noted that more than $80 \%$ of participants who have used several of the interventions judged the respective interventions to be effective). With a high perceived benefit from survey participants and evidence supporting its efficacy (Davis \& Velleman, 2000; Strand \& Debertine, 2000; Edeal \& Gildersleeve-Neumann, 2010), integral stimulation may be an effective treatment option for CAS in a child with autism.

While further scientific research is necessary to support the treatment efficacy of integral stimulation, it is also apparent that practicing SLPs are lacking education on integral stimulation. Perhaps through continuing education and university courses, 
evidence for the efficacy and explanation of the methods of integral stimulation can be presented and become more widely used and recognized around the country.

One of the drawbacks to using integral stimulation with a child with autism is the requirement of imitation. As discussed earlier in this paper, many children with autism demonstrate impaired imitation- limiting the effectiveness of treatments which require a child to attend to a clinician's mouth and imitate the movements required for speech production. It may be possible that a hybrid approach, for example combining integral stimulation or AAC and PROMPT together could be successful for a child given the challenges associated with autism and CAS. Obviously, there is an immense need for further scientific research regarding treatment for CAS in children with autism especially.

Finally, the findings regarding oral-motor exercises for the treatment of CAS in children with autism are concerning. Of the total participants, $28 \%$ reported that they have used oral-motor exercises for this population. Of that $28 \%, 70 \%$ reported a perceived benefit with the use of this treatment. Evidence does not support the use of oral-motor exercise for the treatment of CAS (Lof, 2008). Reasons for this include: children with CAS have adequate oral structure movements for non speech activities (Caruso \& Strand, 1999) and there is no muscle weakness for children with CAS, therefore exercises intended to increase strength in the oral mechanism are unnecessary. The results from the current study are consistent with results from Lof and Watson's survey (2008) which revealed that $85 \%$ of participants $(\mathrm{n}=537)$ indicated using oralmotor exercises for the treatment of speech sound disorders. Perceived benefits cited in Lof and Watson's study included improved tongue elevation, awareness of the 
articulators, tongue strength, lip strength, lateral tongue movements, jaw stabilization, lip and tongue protrusion, drooling control, velopharyngeal competence, and sucking ability - none of which are necessary for speech production (Ruscello, 2008). Although the current study did not specify the perceived benefits reported by participants, it is likely that many of the same benefits would be reported. Participants' responses from the current study as well as responses to Lof and Watson's study demonstrate that SLPs do not have an accurate understanding of the scientific literature on oral-motor exercises and necessitate further education on evidence-based practice for children with CAS.

It is possible that the question (\#28) regarding treatment for CAS and autism may not have yielded clear results. The question was intended to inquire about treatments that have been used with children who have CAS and autism. Although that part of the question was highlighted in bold type, it is possible that participants may have responded to the question based on treatment of children with CAS, and not necessarily autism. It may have been beneficial to divide Question \#28 into two parts; the first part could have addressed knowledge and familiarity with the treatments for CAS only, while the second part could have asked if participants had used the treatments and seen a benefit from the treatment or would be comfortable implementing the treatment for a child with CAS and autism. As the results stand now, it is difficult to tell if the participants read the question carefully enough to recognize that they were to answer with the treatment of a child with CAS and autism in mind, not only CAS.

Answers to the final survey question regarding the model of treatment for CAS revealed that $68 \%$ of participants implement treatment for CAS into an overall 
comprehensive approach for the treatment of autism. Only $9 \%$ indicated that they either targeted the speech sound disorder in isolation or did not target the speech sound disorder in children with autism. These results are encouraging (the percentage of participants who implement an comprehensive approach may have been higher if all participants were involved in treatment $-21 \%$ indicated that this question was not applicable, i.e., they do not participate in treatment). It is important to remember that the primary diagnosis of a child with CAS and autism will always be autism - such a child may also be affected by CAS; however, it is crucial to continue treatment aimed at decreasing the negative impact of autism. As mentioned earlier in this paper, the most effective treatment for autism is a comprehensive treatment program targeting all affected areas of development. Treatment should include early intervention, intensive instruction, repeated and planned teaching opportunities, systematic and developmentally appropriate instruction, family inclusion, ongoing assessment, and instruction in settings with typical peers (National Research Council [NRC]; as cited in Ogletree, Oren, \& Fischer, 2007). For a child with characteristics of CAS in addition to being impacted by autism, treatment such as integral stimulation, PROMPT, or AAC should be added to a comprehensive approach utilizing the principles listed above and suggested by the NRC.

Results of this study have revealed that although most SLPs are incorporating treatment for CAS into a comprehensive treatment approach for autism, there is a wide range of levels of experience with and knowledge of treatments for CAS. Research is greatly needed in order to determine the most effective treatment for CAS in children with autism as well as how best to incorporate the treatment into a comprehensive 
approach. It is suspected that a comprehensive approach such as the Denver Model, which targets all areas of development, together with PROMPT and/or integral stimulation, similar to the approach used in the study by Rogers et al. in 2006, may best serve the children in this population. Further research should be conducted to determine if there is a comprehensive approach that is able to incorporate systematic treatment specifically designed for CAS more effectively than other comprehensive approaches for children with autism. 


\section{Conclusion}

This study was conducted to discover if SLPs are suspecting CAS in children with autism as well as how they are assessing and treating the children. A survey was distributed nationwide through the use of snowball sampling, Facebook discussion pages, and ASHA and Apraxia-Kids e-mail distribution lists. The survey generated 132 responses. It was expected that SLPs would be diagnosing CAS in some children with autism and using a variety of assessment tools and treatment methods with the children. Results revealed that SLPs are suspecting CAS in approximately 1 in 5 children with autism but much fewer children with autism have a diagnosis of CAS. Also, not all survey respondents reported serving children with autism and CAS.

Several factors may have influenced the results regarding number of children with autism and CAS. First, because of the sampling method used, the sample is nonrandomized and may represent a biased group of SLPs. Participants in the study may reflect a higher level of education than the entire population of SLPs in the United States and may also have specialized knowledge and/or training on CAS. As a result, those with increased knowledge of the disorder may suspect it more in children with and without autism than other SLPs in the United States. Results to several questions also suggested that not all participants have a clear understanding of autism and/or CAS as separate disorders. A misunderstanding of one or both of the disorders may result in inaccurate diagnoses of the disorders separately, or if they are occurring together. Results also revealed that SLPs who have worked in the field of speech-pathology the longest are suspecting CAS more often in children with autism than those who have been 
in the field for a shorter number of years. And, as expected, SLPs who serve more children with autism have suspected CAS in more children with autism than those who serve fewer children with autism. Lastly, it should be recognized that the nature of selfreported data is that there is no way to confirm whether not the children with autism reported by the participants to have CAS do indeed fit the diagnostic criteria for the disorder.

The decision of when to assess a child with autism for CAS as well as the assessment tools used varied greatly across participants. The majority of participants indicated that they would begin assessment as soon as specific signs of CAS are noticed; however several participants also indicated that they used a different decision-making process for when to begin assessment. Participants cited 22 different characteristics that are used as diagnostic markers for CAS. However, not all of the traditional diagnostic markers for CAS should necessarily be considered diagnostic markers of CAS in a child with autism (e.g. suprasegmental abnormalities). A few SLPs also reported the use of an incorrect diagnostic marker - weakness or paralysis of the speech mechanism.

With no scientific research to date regarding treatment efficacy for the treatment of CAS in children with autism, SLPs are forced to rely on anecdotal data when selecting a treatment to target CAS in a child with autism. The most common treatment methods that participants have used and are familiar with for the treatment of CAS are AAC and PROMPT. The wording of the question made it difficult to determine if participants reported on the use and knowledge of treatment just for CAS or for children with autism and characteristics of CAS. Either way, participants reported the least knowledge and 
experience with one of the most recent treatments for CAS - integral stimulation.

Although there has not been any research on the use of integral stimulation for children with autism and CAS; several scientific studies have demonstrated effectiveness of the treatment for children with CAS.

Conclusions from this study include the fact that SLPs are suspecting CAS in children with autism. However, they are currently relying on a wide range of assessment and treatment methods, which may be revealing mixed and/or inaccurate results. There is a great need for further research in this area, especially regarding the most effective assessment process and treatment method that should be used with this population.

\section{Limitations of the Current Study}

The largest limitation of this study was the sampling method. Due to cost restrictions, there was not a reliable way to reach the whole population of SLPs in the United States. Snowball sampling can be an effective way to reach a large number of members from a target population (i.e. SLPs working with children from 0-6 years old) when it is impossible to reach the entire population. In order to augment this method, two other methods of survey distribution were also relied upon (Facebook discussion pages and e-mail distribution lists). The sampling methods used in this study were the most cost- and time-effective way to reach a large number of participants; however it led to a non-randomized and possibly biased sample. Although the results of the study yielded valuable information, it may be difficult to draw conclusions that can be applied to the entire population of SLPs in the United States. 
Conclusions from the survey were somewhat limited due to a few problems with the survey questions. Some of the questions in the survey did not provide clear results and a few questions could have been written differently in order to gain more specific information. It also would have been valuable to gather information on numbers of children served just with CAS, not only CAS and autism. If an SLP does not diagnose CAS in many children who are otherwise typically developing, it is unlikely that he/she will suspect CAS in a child with autism. Also, if they have not served many children with CAS, it would be reasonable to expect that their experience with and knowledge of the assessment and treatment practices for CAS may be limited.

The nature of relying on self-reported data from memory also limits conclusions that can be drawn from the survey. A drawback of survey research is that there is no way for the researcher to confirm information reported from participants. In this survey, participants were also asked to respond to questions with children specifically aged birth to 6 who may have had autism and CAS in mind. It is impossible to know whether or not participants consistently answered the survey questions with that specific population in mind.

It also would have been valuable to gain more information on the treatment models used for children with autism, in addition to treatments for children with CAS and autism. The treatment models being used for children with autism could have revealed information on the participants' knowledge of best practice for children with autism. It would have been interesting to find out where on the autism treatment continuum the SLPs are treating children with autism. This information could have provided insight 
into how effective the treatment for CAS is when combined with different approaches to treating autism.

\section{Implications for Future Research}

The results of this study support continued investigation of CAS in children with autism. There is a strong need for the development of clear diagnostic guidelines for CAS in a child with autism. Further studies should help to identify clearer diagnostic markers of CAS in children with autism, especially regarding suprasegmental abnormalities. Case studies of children with CAS and autism may help to determine common characteristics. Retrospective studies of children with CAS who were nonverbal may assist in the development of the early detection of signs of CAS in children with and without autism who are nonverbal. Within groups research design (i.e. different assessment tools used with the same groups of participants) may also help to determine the most sensitive and reliable assessment tools and diagnostic characteristics (especially prosodic markers) to be used with children with CAS and autism.

Finally, longitudinal treatment studies should be conducted in order to determine the most effective treatment approach for children with CAS and autism. Information qualifying the interpretation of SLPs' perceived benefit for specific approaches (especially oral-motor exercises) will help to focus treatment studies with this population. Further studies can also help to identify how an SLP should incorporate treatment for CAS into an overall comprehensive treatment approach, such as the Denver Model, for children with autism and CAS. The current findings have served as an introduction to the 
idea that some children with autism may be affected by apraxia of speech and have helped to identify the immense need for further research and exploration of the topic. 


\section{References}

Adams, L. (1998). Oral-motor and motor-speech characteristics of children with autism. Focus on Autism \& Other Developmental Disabilities, 13, 108-112.

Akshoomoff, N. (2006). Use of the Mullen Scales of Early Learning for the assessment of young children with autism spectrum disorders. Child Neuropsychology, 12, 269-277.

Aldred, C., Green, J., \& Adams, C. (2004). A new social communication intervention for children with autism: Pilot randomized controlled treatment study suggesting effectiveness. Journal of Child Psychology and Psychiatry, 45, 1420-1430.

American Psychiatric Association. (2000). Diagnostic and statistical manual of mental disorders ( $4^{\text {th }}$ ed.). Washington, D.C: American Psychiatric Association.

American Speech-Language and Hearing Association. (2005). Principles for speechlanguage pathologists in diagnosis, assessment, and treatment of autism spectrum disorders across the life span [Technical Report]. Retrieved November 18, 2009 from www.asha.org/policy.

American Speech-Language and Hearing Association. (2007a). Childhood apraxia of speech [Position Statement]. Retrieved September 31, 2009 from www.asha.org/policy.

American Speech-Language and Hearing Association. (2007b). Childhood apraxia of speech [Technical Report]. Retrieved September 31, 2009 from www.asha.org/policy. 
Anderson, D.K., Lord, C., Risi, S., Shulman, C., Welch, K., DiLavore, P.S., Thurm, A., \& Pickles, A. (2007). Patterns of growth in verbal abilities among children with autism spectrum disorder. Journal of Consulting and Clinical Psychology, 75, 594-604.

Bayley, N. (1993). Bayley scales of infant development ( $2^{\text {nd }}$ ed.). San Antonio, TX: Psychological Corp.

Binder, C. (1988). Precision teaching: Measuring and attaining exemplary academic achievement. Youth Policy Journal, 10)7), 12015.

Bondy, A.S., \& Frost, L.A. (1994). The picture exchange communication system. Focus on Autistic Behavior, 9, 1-19.

Carr, E.G. \& Kologinsky, E. (1983). Acquisition of sign language by autistic children II: Spontaneity and generalization effects. Journal of Applied Behavior Analysis, 16, 297-314.

Chumpelik, D. (1984). The PROMPT system of therapy: Theoretical framework and applications for developmental apraxia of speech. Seminars in Speech and Language, 5, 139-156.

Cumley, G.D., \& Swanson, S. (1999). Augmentative and alternative communication options for children with developmental apraxia of speech: Three case studies. Augmentative and Alternative Communication, 15, 110-125.

Davis, B.L., Jakielski, K.J., \& Marquardt, T.P. (1998). Developmental apraxia of speech: Determiners of differential diagnosis. Clinical Linguistics and Phonetics, 12, 25 45. 
Davis, B.L., \& Velleman, S.L. (2000). Differential diagnosis and treatment of developmental apraxia of speech in infants and toddlers. Infant-Toddler Intervention, 10, 177-192.

Dawson, G., Rogers, S., Munson, J., Smith, M., Winter, J., Greenson, J., Donaldson, A., \& Varley, J. (2010). Randomized, controlled trial of an intervention for toddlers with autism: The Early Start Denver Model. Pediatrics, 125, 17-23.

Dawson, G., Toth, K., Abbott, R., Osterling, J., Munson, J., Estes, A., \& Liaw, J. (2004). Early social attention impairments in autism: Social orienting, joint attention, and attention to distress. Developmental Psychology, 40, 271-283.

Delprato, D.J. (2001). Comparisons of discrete-trial and normalized behavioral language intervention for young children with autism. Journal of Autism and Developmental Disorders, 31, 315- 325.

Denckla, M.B. (1985). Revised Neurological Examination for Subtle Signs. Psychopharmacology Bulletin, 21, 773-800.

Dewey, D., Roy, E., Square-Storer, P.A., \& Hayden, D. (1988). Limb and oral praxic abilities of children with verbal sequencing deficits. Developmental Medicine and Child Neurology, 30, 743-751.

Dillman, D.A. (2000). Mail and Internet Surveys. New York: Wiley.

Drash, P.W., High, R.L., \& Tudor, R.M. (1999). Using mand training to establish and echoic repertoire in young children with autism. The Analysis of Verbal Behavior, $16,29-44$. 
Dziuk, M.A., Gidley Larson, J.C., Apostu, A., Mhone, E.M., Denckla, M.B., \& Mostofsky, S.H. (2007). Dyspraxia in autism: association with motor, social, and communicative deficits. Developmental Medicine \& Child Neurology, 49, 734739.

Eaves, L.C., \& Ho, H.H. (2004). The very early identification of autism: Outcome to age 4 1⁄2 -5. Journal of Autism and Developmental Disorders (34), 367-378.

Edeal, D.M. \& Gildersleeve-Neumann, C.A. (2010). Integral stimulation deconstructed: The importance of production frequency in therapy. Manuscript under revision.

Erba, H.W. (2000). Early intervention programs for children with autism: Conceptual frameworks for implementation. American Journal of Orthopsychiatry, 70, 82-94.

Fabrizio, M.A., Pahl, S., \& Moors, A. (2002). Improving speech intelligibility through precision teaching. Journal of Precision Teaching and Celeration, 18, 25-27.

Forrest, K. (2003). Diagnostic criteria of developmental apraxia of speech used by clinical speech-language pathologists. American Journal of Speech-Language Pathology, 12, 376-380.

Foxx, R. (2008). Applied behavior analysis treatment of autism: The state of the art. Child and Adolescent Psychiatric Clinics of North America, 17(4), 821-834.

Freed, D.B., Marshall, R.C., \& Frazier, K.E. (1997). Long-term effectiveness of PROMPT treatment in a severely apractic-aphasic speaker. Aphasiology, 11, 365372. 
Gernsbacher, M.A., Sauer, E.A., Geye, H.M., Schweigert, E.K., \& Goldsmith, H.H. (2008). Infant and toddler oral- and manual-motor skills predict later speech fluency in autism. Journal of Child Psychology and Psychiatry, 49, 43-50.

Goldstein, H. (2002). Communication intervention for children with autism: A review of treatment efficacy. Journal of Autism and Developmental Disorders, 32, 373396.

Greenspan, S.I., \& Wieder, S. (1997b). Developmental patterns and outcomes in infants and children with disorders in relating and communicating: A chart review of 200 cases of children with autistic spectrum diagnoses. Journal of Developmental and Learning Disorders, 1, 87-141.

Greenspan, S.I., \& Wieder, S. (1998). The child with special needs: Encouraging intellectual and emotional growth. Reading, MA: Addison-Wesley.

Hancock, T.B., \& Kaiser, A.P. (2002). The effects of trainer-implemented enhanced milieu teaching on the social communication of children with autism. Topics in Early Childhood Special Education, 22, 39-54.

Hall, P.K. (2000). A letter to the parent(s) of a child with developmental apraxia of speech part I: Speech characteristics of the disorder. Language, Speech and Hearing Services in Schools, 31, 169-172.

Hayden, D., Wetherby, A., \& Prizant, B.M. (1999). Early motor control scales. Chicago: Applied Symbolix. 
Helfrich-Miller, K.R. (1983). The use of melodic intonation therapy with developmentally apraxic children: A clinical perspective. Journal of the Pennsylvania Speech-Language-Hearing Association, 16, 11-15.

Helfrich-Miller, K.R. (1994). A clinical perspective: Melodic intonation therapy for developmental apraxia. Clinics in Communication Disorders, 4, 175-182.

Hoyson, M., Jamieson, B., \& Strain, P.S. (1984). Individualized group instruction of normally developing autistic-like children: The LEAP curriculum model. Journal of the Division for Early Childhood, 8, 157-172.

Jansiewicz, E.M., Goldberg, M.C., Newschaffer, C.J., Denckla, M.B., Landa, R., \& Mostofsky, S.H. (2006). Motor signs distinguish children with high functioning autism and asperger's syndrome from controls. Journal of Autism and Developmental Disorders, 36, 613-621.

Kaiser, A.P., Hancock, T.B., \& Nietfeld, J.P. (2000). The effects of parent-implemented enhanced milieu teaching on the social communication of children who have autism. Early Education and Development, 11, 423-446.

Kaufman, N., \& Kasper, T.S. (n.d.). Shaping verbal language for children on the spectrum of autism who also exhibit apraxia of speech. Retrieved from http://www.apraxiakids.org/site/c.chKMIOPIIsE/b.980831/apps/s/content.asp?ct=3587661

Koegel, L.K., Koegel, R.L., Harrower, J.K., \& Carter, C.M. (1999). Pivotal response intervention I: Overview of approach. The Journal of the Association for Persons with Severe Handicaps, 24, 174-185. 
Koegel, R.L., Sze, K.M., Mossman, A., Koegel, L.K., Brookman-Frazee, L. (2006). First words: Getting verbal communication started. In R. L. Koegel \& L.K. Koegel (Eds.), Pivotal response treatments for autism (pp. 141-159). Baltimore, Maryland: Paul H. Brookes Publishing Co.

Kornse, D., Manni, J., Rubenstein, H., \& Graziani, L. (1981). Developmental apraxia of speech and manual dexterity. Journal of Communication Disorders, 14, 321-330.

Kumin, L. (2006). Speech intelligibility and childhood verbal apraxia in children with Down syndrome. Down Syndrome Research and Practice, 10, 10-22.

Light, J.C., Roberts, B., Dimarco, R., \& Greiner, N. (1998). Augmentative and alternative communication to support receptive and expressive communication for people with autism. Journal of Communication Disorders, 31, 153-180.

Lof, G.L., \& Watson, M.M. (2008). A nationwide survey of nonspeech oral motor exercise use: Implications for Evidence-Based Practice. Language, Speech, and Hearing Services in Schools, 39, 392-407.

Lovaas, O.I., Koegel, R., Simmons, J.Q., \& Long, J.S. (1973). Some generalization and follow-up measures on autistic children in behavior therapy. Journal of Applied Behavior Analysis, 6, 131-166.

Lovaas, O.I. \& Smith, T. (1989). A comprehensive behavioral theory of autistic children: Paradigm for research and treatment. Behavior Therapy and Experimental Psychiatry, 20, 17-29. 
Marquardt, T.P., Jacks, A., \& Davis, B.L. (2004). Token-to-token variability in developmental apraxia of speech: Three longitudinal case studies. Clinical Linguistics \& Phonetics, 18, 127-144.

McCauley, R.J., \& Strand, E.A. (2008). A review of standardized tests of nonverbal oral and speech motor performance in children. American Journal of SpeechLanguage Pathology, 17, 81-91.

Mesibov, G.B. (1996). Division TEACCH: A collaborative model program for service delivery, training and research for people with autism and related communication handicaps. In M.C. Roberts (Ed.), Model programs in child and family mental health (pp. 215-230). Hillsdale, NJ: Lawrence Erlbaum.

Miller, S.B., \& Toca, J.M. (1979). Melodic intonation therapy: A case study of an experimental language program for an autistic child. The Journal of Clinical Psychiatry, 40, 201-203.

Mullen, E.M. (1995). Mullen Scales of Early Learning. Circle Pines, MN: American Guidance Service Inc.

Mundy, P., Sigman, M., \& Kasari, C. (1990). A longitudinal study of Joint attention and language development in autistic children. Journal of Autism and Developmental Disorders, 20, 115-128.

Mundy, P., \& Vaughan, A. (2007). Joint attention and its role in the diagnostic assessment of children with autism. Assessment for Effective Intervention, 27, 5760. 
Murdoch, B., Porter, S., Younger, R., \& Ozanne, A. (1984). Behaviours identified by South Australian clinicians as differentially diagnostic of developmental articulatory dyspraxia. Australian Journal of Human Communication Disorders, $12,55-70$.

Nadel, J., \& Aouka, N. (2006). Imitation: Some cues for intervention approaches in autism spectrum disorders. In T. Charman, \& W. Stone (Eds.), Social \& communication development in autism spectrum disorders: Early identification, diagnosis, \& intervention (pp. 219-235). New York, NY: Guilford Press.

Nazarali, N., Glazebrook, C.M., \& Elliott, D. (2009). Movement planning and reprogramming in individuals with autism. Journal of Autism and Developmental Disorders, 39, 1401-1411.

Newmeyer, A.J., Grether, S., Grasha, C., White, J., Akers, R., Aylward, C., Ishikawa, K., $\&$ de Grauw, T. (2007). Fine motor function and oral-motor imitation skills in preschool-age children with speech-sound disorders. Clinical Pediatrics, 46, 604612.

Odell, K., \& Shriberg, L. (2001). Prosody-voice characteristics of children and adults with apraxia of speech. Clinical Linguistics \& Phonetics, 15, 275- 307.

Ogletree, B.T., Oren, T., \& Fischer, M.A. (2007). Examining effective intervention practices for communication impairment in autism spectrum disorder. Exceptionality, 15, 233-247.

Page, J., \& Boucher, J. (1998). Motor impairments in children with autistic disorder. Child Language Teaching and Therapy, 14, 233-259. 
Preston, D., \& Carter, M. (2009). A review of the efficacy of the picture exchange communication system intervention. Journal of Autism and Developmental Disorders, 39, 1471-1486.

Prizant, B. (1996). Brief report: Communication, language, social, and emotional development. Journal of Autism and Developmental Disorders, 26, 173- 178.

Prizant, B., \& Wetherby, A. (1988). Providing services to children with autism (ages 0 to 2 years) and their families. Topics in Language Disorders. 9, 1-23.

Rapin, I. (1996). Neurological examination. In I. Rapin (Ed.), Preschool children with inadequate communication (pp. 98-122). London: MacKeith Press.

Receveur, C., Lenoir, P., Desombre, H., Roux, S., Barthelemy, C., \& Malvy, J. (2005). Interaction and imitation deficits from infancy to 4 years of age in children with autism: A pilot study based on videotapes. Autism, 9, 69-82.

Rogers, S.J., Hall, T., Osaki, D., Reaven, J., \& Herbison, J. (2000). A comprehensive, integrated, educational approach to young children with autism and their families. In S.L. Harris \& J.S. Handleman (Eds.), Preschool education programs for children with autism ( $3^{\text {rd }}$ ed.). Austin, TX: Pro-Ed.

Rogers, S., Hayden, D., Hepburn, S., Charlifue-Smith, R., Hall, T., \& Hayes, A. (2006). Teaching young nonverbal children with autism useful speech: A pilot study of the Denver model and PROMPT interventions. Journal of Autism and Developmental Disorders, 36, 1007-1024. 
Rogers, S.J., Hepburn, S.L., Stackhouse, T., \& Wehner, E. (2003). Imitation performance in toddlers with autism and those with other developmental disorders. Journal of Child Psychology and Psychiatry, 44, 763-781.

Rogers, S.J., \& Vismara, L.A. (2008). Evidence-based comprehensive treatments for early autism. Journal of Clinical Child \& Adolescent Psychology, 37, 8-38.

Rosenbek, J., Lemme, M., Ahern, M., Harris, E., \& Wertz, T. (1973). A treatment for apraxia of speech in adults. Journal of Speech and Hearing Disorders, 38, 462472.

Ross, D.E., \& Greer, R.D. (2003). Generalized imitation and the mand: inducing first instances of speech in young children with autism. Research in Developmental Disabilities, 24, 58-74.

Ruscello, D. (2008). Nonspeech oral motor treatment issues related to children with developmental speech sound disorders. Language, Speech, and Hearing Services in Schools, 39, 380-391.

Sallows, G.O., \& Graupner, T.D. (2005). Intensive behavioral treatments for children with autism: Four-year outcome and predictors. American Journal on Mental Retardation, 110, 417-438.

Schoen, E., Paul, R., \& Chawarska, K. (2009). Vocal production in toddlers with autism spectrum disorders. In R. Paul \& P. Flipsen (Eds.), Speech sound disorders in children. San Diego: Plural.

Schopler, E., Reichler, R.J., \& Renner, B.R. (1988). Childhood Autism Rating Scale. Western Psychological Resources. 
Seal, B.C., \& Bonvillian, J.D. (1997). Sign language and motor functioning in students with autistic disorder. Journal of Autism and Developmental Disorders, 27, 437466.

Shriberg, L., Paul, R., McSweeney, J., Klin, A., Cohen, D., \& Volkmar, F. (2001). Speech and prosody characteristics of adolescents and adults with high functioning autism and Asperger syndrome. Journal of Speech, Language, and Hearing Research, 44, 1097-1115.

Sigman, M., \& McGovern, C.W. (2005). Improvement in cognitive and language skills from preschool to adolescence in autism. Journal of Autism and Developmental Disorders, 35, 15-23.

Skinner, B.J. (1968). The technology of teaching. New York: Appleton-Century-Crofts.

Smith, M., Rogers, S., \& Dawson, G. (2008). The Early Start Denver Model: A comprehensive early intervention approach for toddlers with autism. In J.S. Handleman \& S.L. Harris (Eds), Preschool education programs for children with autism (pp. 65-101). Austin, TX: Pro-Ed Corporation, Inc.

Smith, T. (2008). Empirically supported and unsupported treatments for autism spectrum disorders. The Scientific Review of Mental Health Practice, 6, 3-20.

Smith, T., Groen, A.D., \& Wynn, J.W. (2000). Randomized trial of intensive early intervention for children with pervasive developmental disorder. American Journal on Mental Retardation, 105, 269-285. 
Stevens, M.C., Fein, D.A., Dunn, M., Allen, D., Waterhouse, L.H., Feinstein, C., \& Rapin, I. (2000). Subgroups of children with autism by cluster analysis: A longitudinal examination. Journal of American Academy of Child Psychiatry, 39, 346- 352.

Stone, W.L., \& Yoder, P.J. (2001). Predicting spoken language level in children with autism spectrum disorders. Autism, 5, 341-361.

Strain, P.S., \& Hoyson, M. (2000). The need for longitudinal, intensive social skill intervention: LEAP follow-up outcomes for children with autism. Topics in Early Childhood Special Education, 20(2), 116-122.

Strand, E.A., \& Debertine, P. (2000). The efficacy of integral stimulation intervention with developmental apraxia of speech. Journal of Medical Speech-Language Pathology, 8, 295-300.

Strand, E.A., \& Skinder, A. (1999). Treatment of developmental apraxia of speech: Integral stimulation methods. In A.J. Caruso \& E.A. Strand (Eds.), Clinical management of motor speech disorders in children (pp. 109-148). New York: Thieme Medical Publishers, Inc.

Strand, E.A., Stoeckel, R., \& Baas, B. (2006). Severe childhood apraxia treatment efficacy study. Journal of Medical Speech-Language Pathology, 14, 297-307.

Subiaul, F., Lurie, H., Romansky, K., Klein, T., Holmes, D., \& Terrace, H. (2007). Cognitive imitation in typically-developing 3- and 4-year olds and individuals with autism. Cognitive Development, 22, 230-243. 
Tager-Flusberg, H., Paul, R., \& Lord, C. (2005). Language and communication in autism. In F. Volkmar, R. Paul, A. Klin \& D. Cohen (Eds.), Handbook of autism and pervasive developmental disorders (pp. 335-364). New York: Wiley.

Teverovsky, E.G., Bickel, J.O., \& Feldman, H.M. (2009). Functional characteristics of children diagnosed with childhood apraxia of speech. Disability and Rehabilitation, 31, 94-102.

Thoonen, G., Maassen, B., \& Wit, J. (1996). The integrated use of maximum performance tasks in differential diagnostic evaluations among children with motor speech disorders. Clinical Linguistics \& Phonetics, 10, 311-336.

Thorndike, R.L., Hagen, E.P., \& Sattler, J.M. (1986). Stanford-Binet Intelligence Scale: Forth Edition. Itasca, IL: Riverside Publishing.

Velleman, S., \& Shriberg, L. (1999). Metrical analysis of the speech of children with suspected developmental apraxia of speech. Journal of Speech, Language, and Hearing Research, 42, 1444-1460.

Velleman, S. L., Andrianopoulos, M. V., Boucher, M., Perkins, J., Averback, K. E., Currier, A., et al. (2009). Motor speech disorders in children with autism. In R. Paul \& P. Flipsen (Eds.), Speech sound disorders in children. San Diego: Plural. Wetherby, A.M., \& Prutting, C.A. (1984). Profiles of communicative and cognitivesocial abilities in autistic children. Journal of Speech and Hearing Research, 27, 364-377. 
Wetherby, A.M., Watt, N., \& Morgan, L. (2007). Social communication profiles of children with autism spectrum disorders late in the second year of life. Journal of Autism and Developmental Disorders, 37, 960-975.

Williams, G., \& Greer, R.D. (1993). A comparison of verbal-behavior and linguistic communication curricula for training developmentally delayed adolescents to acquire and maintain vocal speech. Behaviorology, 1, 31-46.

Williams, J.H.G., Whiten, A., \& Singh, T. (2004). A systematic review of action imitation in autistic spectrum disorder. Journal of Autism and Developmental Disorders, 34, 285-299.

Yoder, P., \& McDuffie, A. (2006). Teaching young children with autism to talk. Seminars in speech and language, 27, 161- 172. 


\section{Appendix A}

Consent Letter for E-mail Distribution Lists

\section{Dear SLP,}

My name is Elsa Dawson and I am a master's student in Speech-Language Pathology at Portland State University. If you are an SLP working with children ages birth to 3 or 4-6 yrs, please continue reading. Otherwise, your participation is not requested at this time.

You are invited to participate in a research study through which I am hoping to learn the prevalence of co-occurring autism and childhood apraxia of speech (CAS) in the United States, as well as the current assessment and treatment practices for this population.

If you decide to participate, you will be asked to complete a survey on assessment and treatment practices of children with autism and CAS which will take about 10-15 minutes. The survey has been designed to take the least amount of time possible while still gaining valuable information. We appreciate that you are taking valuable time out of your work day to complete this survey.

The link below will direct you to the survey. Please complete the survey by March $20^{\text {th }}$, 2010. Thank you, in advance, for your time and thoughtfulness while completing our survey.

Sincerely,

Elsa Dawson

Graduate Student, Speech-Language Pathology

Portland State University

To begin the survey, click here:

http://www.surveygizmo.com/s/237858/o06si 


\section{Appendix B}

Consent Letter for Facebook Discussion Pages

Hi everyone,

My name is Elsa Dawson and I am a $2^{\text {nd }}$ year master's student in Speech-Language Pathology at Portland State University. If you are an SLP working with children ages birth to 3 or 4-6 yrs, please continue reading. Otherwise, your participation is not requested at this time.

I am working on my thesis, which is a survey on the assessment and treatment practices of children with autism and childhood apraxia of speech (CAS). Please follow the link below to access my survey. It will take about 10-15 minutes to complete. Please complete the survey by March $20^{\text {th }}, 2010$. Thank you, in advance, for taking the time out of your day to contribute to this area of research!

Sincerely,

Elsa Dawson

Graduate Student, Speech-Language Pathology

Portland State University

To begin the survey, click here:

http://www.surveygizmo.com/s/237858/o06si 


\author{
Appendix C \\ Consent Letter for Snowball Sampling
}

\title{
Dear SLP,
}

My name is Elsa Dawson and I am a master's student in Speech-Language Pathology at Portland State University. You are likely receiving this e-mail through your contacts in Portland, OR. If you are currently working with children ages birth to 3 or 4-6 yrs, please continue reading. Otherwise, your participation is not requested at this time.

You are invited to participate in a research study through which I am hoping to learn the prevalence of childhood apraxia of speech (CAS) in children with autism in the United States, as well as the current assessment and treatment practices for this population.

If you decide to participate, you will be asked to complete a survey on assessment and treatment practices of children with autism and CAS which will take about 10-15 minutes. We appreciate that you are taking valuable time out of your work day to complete this survey.

The link below will direct you to the survey. Please complete the survey by March $20^{\text {th }}$, 2010. Due to the sampling method being used, I am unable to send a reminder e-mail to you regarding the survey. Because of this, please complete the survey as soon as possible.

Thank you, in advance, for your time and thoughtfulness while completing our survey.

Lastly, as snowball sampling is being used to distribute the survey, if you are willing, please forward this e-mail to other SLPs who it may apply to. Your help in creating a large and diverse sample is greatly appreciated! THANK YOU!

Sincerely,

Elsa Dawson

Graduate Student, Speech-Language Pathology

Portland State University

To begin the survey, click here:

http://www.surveygizmo.com/s/237858/o06si 
Appendix D

Autism and Childhood Apraxia of Speech Survey

\section{Informed Consent}

This study is being conducted in partial fulfillment of the requirements for a master's degree in Speech-Language Pathology, and is under the supervision of Dr. Christina Gildersleeve-Neumann, Associate Professor in the Department of Speech and Hearing at Portland State University.

Any information that is obtained through this study will be kept anonymous. Your participation is voluntary and your decision to participate will not affect your relationship with Portland State University. If you decide to take part in the study, you may choose to withdraw at any time without penalty.

If you have concerns or problems about your participation in this study or your rights as a research subject, please contact the Human Subjects Research Review Committee, office of Research and Sponsored Projects, 600 Unitus Bldg., Portland State University, (503) 725-4288 / 1-877-480-4400. If you have questions about the study itself, contact Elsa Dawson at dawsone@pdx.edu.

By clicking "Click to next page" below, you indicate that you have read and understood the above information and agree to take part in this study.

Demographic Information

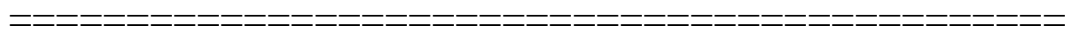

1. Please list your degrees (including your major and year of graduation).

BA

$$
\text { Major Graduation year }
$$

MA/MS

Ph.D.

Other

2. How long have you been a certified Speech-Language Pathologist? (Drop-down menu)

3. How many years have you worked as an SLP in your current setting? (Drop-down menu)

4. In what state do you currently work? (Drop-down menu) 
5. What population do you currently serve? (Please check both boxes if you work with children from both age groups)

( ) Birth to 3 yrs

( ) $4-6$ yrs

6. What is your work setting?

( ) Birth-to-three center

( ) Developmental Preschool

( ) County/State early intervention services

( ) Medical Center/ Hospital-Based Service

( ) University Clinic

() Private Practice

( ) Other/Please specify:

7. Who do you collaborate with? (Check all that apply)

( ) Psychologist

( ) Autism Specialist

( ) Applied Behavior Analyst

( ) Developmental Pediatrician

( ) Family Resource Specialist

( ) Special Educator

( ) General Educator

( ) Neurologist

( ) Occupational Therapist

( ) Physical Therapist

( ) Audiologist

( ) Gastroenterologist

( ) Sleep Disorders Specialist

( ) Other/Please specify:

( ) None

8. Do you work in an urban or rural area?

( ) Urban

( ) Rural

9. How many children do you currently serve? Or, if you are on an assessment team, approximately how many children do you evaluate per month?

10. How many of those children are diagnosed with a primary medical diagnosis of autism (meets criteria according to the DSM IV')? 
${ }^{1}$ Autism is defined as having qualitative impairments in social interaction and communication as well as restricted, repetitive or stereotyped behaviors, interests, or activities.

11. How many of those children with autism are considered nonverbal (i.e. acquire less than 5 verbal words after 3 months of intervention)?

12. How many of the children with autism who you serve have a speech sound disorder (i.e. an articulatory or phonological disorder)?

13. How many of the children with autism and a speech sound disorder do you suspect have Childhood Apraxia of Speech (CAS)?

14. How many of those children have been given a diagnosis of CAS?

15. How many of the children with autism who you suspect have CAS or who have been diagnosed with CAS are considered nonverbal (i.e. acquire less than 5 verbal words after 3 months of intervention)?

Diagnostic Criteria

For questions 14-17 please select if you [strongly disagree, somewhat disagree, are undecided, somewhat agree, or strongly agree] with the following statements.

16. According to the DSM-IV, a child must exhibit qualitative impairments in social interaction and communication as well as restricted, repetitive, or stereotyped behaviors, interests, or activities. If you see a child with a core deficit in the area of pragmatics, do you feel that that is sufficient for a diagnosis of autism?

( ) Strongly Disagree

( ) Somewhat Disagree

() Undecided

( ) Somewhat Agree

( ) Strongly Agree 
17. Children with autism who are nonverbal frequently have CAS.

( ) Strongly Disagree

( ) Somewhat Disagree

( ) Undecided

( ) Somewhat Agree

( ) Strongly Agree

18. Effective treatment for CAS should show immediate improvement.

( ) Strongly Disagree

( ) Somewhat Disagree

( ) Undecided

( ) Somewhat Agree

( ) Strongly Agree

19. According to ASHA's 2007 technical report on CAS, the following areas have been highlighted as specific areas of deficit: inconsistent error production on both consonants and vowels; lengthened and impaired co-articulatory transitions between sounds and syllables; and inappropriate prosody. Do you feel that all three of these areas must be impaired in order to make a diagnosis of CAS?

( ) Strongly Disagree

( ) Somewhat Disagree

( ) Undecided

( ) Somewhat Agree

( ) Strongly Agree

20. For how many of the children identified or suspected to have autism and CAS did you diagnose or suspect the CAS?

21. If you were not the one to identify CAS, for how many of the children did you confirm this diagnosis? 
22. If you suspect that a child with autism has CAS, when do you begin assessment for CAS? (You may select more than one).

( ) If the child is still nonverbal by a certain age. If so, what age?

( ) If the child is not developing speech as a result of other treatment techniques after a certain amount of time. If so, after how long?

( ) As soon as you notice a certain number of signs of CAS. If so, at least how many signs do you look for?

( ) As soon as you notice specific signs of CAS.

() If a child is nonverbal.

( ) Other/Please specify:

23. If you answered "As soon as you notice specific signs of CAS" on question \#22 above, which signs do you watch for? (Select all that apply) If not, please select "Not applicable."

( ) Inconsistent production of speech sounds

( ) Limited speech sound repertoire

( ) Groping with the speech mechanism

( ) Decrease in intelligibility with increasing linguistic complexity

( ) Slow progress in treatment

() Difficulty combining and sequencing phonemes

( ) Difficulty with imitation

( ) Difficulty with nonspeech oral motor tasks

( ) Difficulty producing novel words

( ) Inappropriate prosody

( ) Vowel deviations

( ) Other/Please specify:

( ) Weakness or paralysis of the speech mechanism

( ) Omitting sounds and syllables in speech

( ) Not applicable 
24. Which assessments have you used to assess CAS in children with autism? (Check all that apply)

() Standardized articulation test

( ) Standardized phonological processing test

( ) Diadochokinetic tasks

( ) Connected speech sample

( ) Oral mechanism exam

( ) Nonspeech oral motor tasks

( ) Trial period of intervention

( ) Imitation of nonsense words

( ) Imitation of multisyllabic words

() Imitation of phrases

( ) Administration of the Apraxia Profile

( ) Administration of the Screening Test of Developmental Apraxia of Speech-2

( ) Administration of the Verbal Motor Production Assessment for Children

( ) Other/Please specify:

( ) Administration of the Kaufman Speech Praxis Test

( ) None

25. Check the characteristics that you would use to make a diagnosis of CAS in a child with autism.

( ) Inconsistent production of speech sounds

( ) Limited speech sound repertoire

( ) Groping with the speech mechanism

( ) Decrease in intelligibility with increasing linguistic complexity

( ) Slow progress in treatment

( ) Difficulty combining and sequencing phonemes

( ) Difficulty with imitation

( ) Difficulty with nonspeech oral motor tasks

( ) Omitting sounds and syllables in speech

( ) Difficulty producing novel words

( ) Inappropriate prosody

( ) Weakness or paralysis of the speech mechanism

( ) Other/Please specify:

( ) Vowel deviations

26. If known, approximately how many of the children you serve with autism and CAS exhibit limb apraxia 2 ?

( ) Not applicable

( ) Approximate number of children:

${ }^{2}$ Limb apraxia is defined as impaired volitional movements of the limbs, mild delays in motor development, and/or mildly low muscle tone. 
27. If known, approximately how many of the children you serve with autism and CAS exhibit oral apraxia ${ }^{3}$ ?

() Not applicable

( ) Approximate number of children:

${ }^{3}$ Oral apraxia is defined as impaired volitional oral movements (imitated or elicited postures or sequences such as smile-kiss) and groping

Intervention

28. For each of the following treatment techniques, please check which you have implemented with a child with autism and CAS, which you are familiar with, which you would be comfortable implementing, and which treatments you have seen benefit a child with autism and CAS.

knowledge

Have implemented? Familiar? Comfortable? Benefit? No

Integral Stimulation

PROMPT

Melodic Intonation

Therapy

Non-speech oral motor

exercise

Augmentative and Alternative

Communication (AAC)

Behavioral Modification

techniques (e.g. ABA)

Kaufman approach

Phonological cycling

Phonetic placement

approach

29. If you have used a different treatment technique for children with autism and CAS (that was not listed in \#28 above), please name and describe the treatment(s) below.

( ) Not applicable

( ) Name and/or description of treatment technique: 
30. As the SLP do you implement this treatment...

( ) as part of a comprehensive treatment approach (i.e. you incorporate treatment for the speech sound disorder into your overall treatment approach for children with autism)?

( ) in isolation (i.e. you only target the speech sound disorder during a session when working with children with CAS and autism)?

( ) in isolation while other members of the treatment team use different treatment approaches (i.e. as the SLP, you target the speech sound disorder while the learning specialist or autism specialist implement more traditional treatment to target the communication impairments resulting from autism)?

( ) I do not target the speech sound disorder directly.

( ) Not applicable/I do not provide treatment.

31. How do you select the treatment method that you will use to target CAS in children with autism? (You may select more than one)

( ) Personal clinical judgment

() What I learned in graduate school about CAS

( ) From information in continuing education courses

( ) Ease of implementation/ most available materials

( ) Research-based information

( ) Suggestion from other clinician(s)

( ) In collaboration with the child's family

( ) Results of assessment

( ) Other/Please specify:

Thank You!

Thank you for agreeing to participate in our survey. Your input will be very valuable to the current research in the area of autism and childhood apraxia of speech. Your experiences with this population, together with other participants' experiences will, hopefully, help to identify a need for clearer assessment and treatment guidelines for children who fall into this category. As we all know, early identification and early, effective treatment results in the best prognosis for these children.

Thank you, again, for your participation. If you would like to have the results of this survey sent to you, please send an email to the researcher at dawsone@pdx.edu.

Sincerely,

Elsa Dawson

Graduate Student, Speech-Language Pathology

Portland State University 